\title{
Feasibility of using Big Area Additive Manufacturing to Directly Manufacture Boat Molds
}

\section{MDF USER AGREEMENT \\ FINAL REPORT \\ NN-17-1062}

Approved for Public Release.

Distribution is Unlimited.
Brian Post

Phillip Chesser

Randall Lind Matthew Sallas Lonnie J. Love

January 2018 


\section{DOCUMENT AVAILABILITY}

Reports produced after January 1, 1996, are generally available free via US Department of Energy (DOE) SciTech Connect.

Website http://www.osti.gov/scitech/

Reports produced before January 1, 1996, may be purchased by members of the public from the following source:

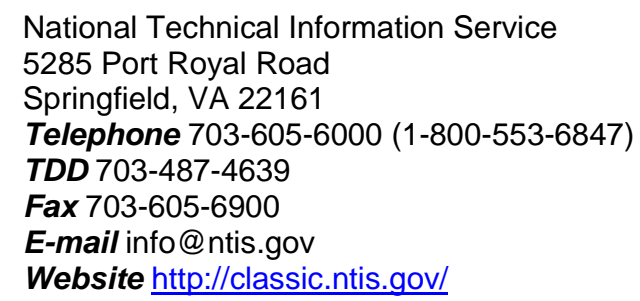

Reports are available to DOE employees, DOE contractors, Energy Technology Data Exchange representatives, and International Nuclear Information System representatives from the following source:

Office of Scientific and Technical Information

PO Box 62

Oak Ridge, TN 37831

Telephone 865-576-8401

Fax 865-576-5728

E-mail reports@osti.gov

Website http://www.osti.gov/contact.html

This report was prepared as an account of work sponsored by an agency of the United States Government. Neither the United States Government nor any agency thereof, nor any of their employees, makes any warranty, express or implied, or assumes any legal liability or responsibility for the accuracy, completeness, or usefulness of any information, apparatus, product, or process disclosed, or represents that its use would not infringe privately owned rights. Reference herein to any specific commercial product, process, or service by trade name, trademark, manufacturer, or otherwise, does not necessarily constitute or imply its endorsement, recommendation, or favoring by the United States Government or any agency thereof. The views and opinions of authors expressed herein do not necessarily state or reflect those of the United States Government or any agency thereof. 
Advanced Manufacturing Office

Energy and Transportation Sciences Division

Feasibility of Using Big Area Additive Manufacturing to Directly Manufacture Boat Molds

\author{
Brian Post \\ Phillip Chesser \\ Randall Lind \\ Matthew Sallas \\ Lonnie J. Love
}

Date Published:

January 4, 2018

\author{
Prepared by \\ OAK RIDGE NATIONAL LABORATORY \\ Oak Ridge, TN 37831-6283 \\ managed by \\ UT-BATTELLE, LLC \\ for the \\ US DEPARTMENT OF ENERGY \\ under contract DE-AC05-00OR22725
}

Approved For Public Release 


\section{CONTENTS}

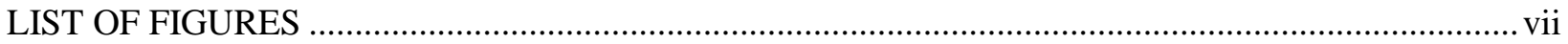

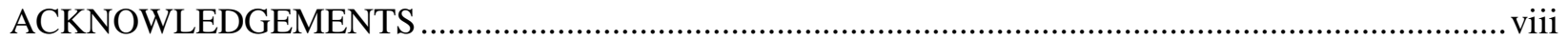

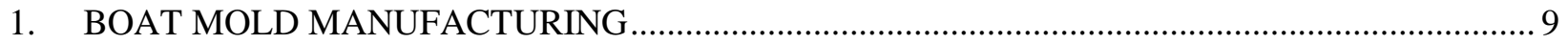

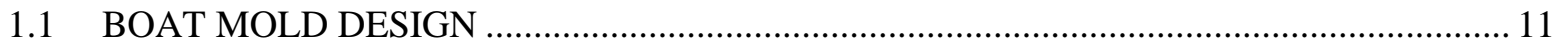

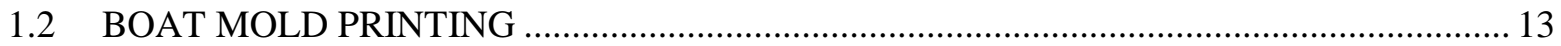

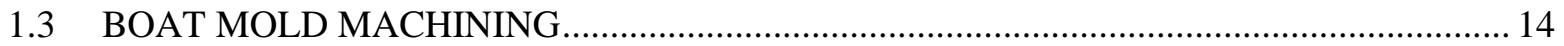

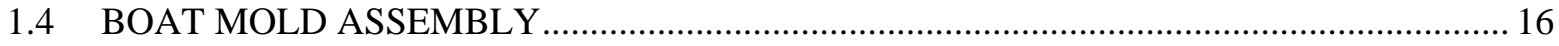

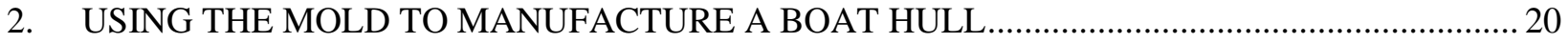

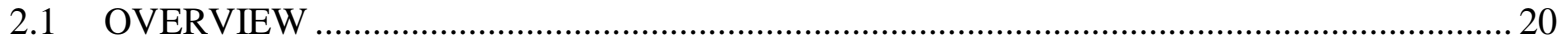

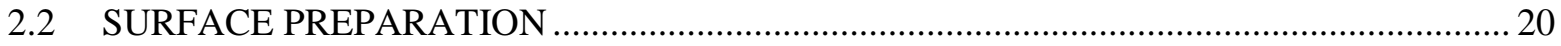

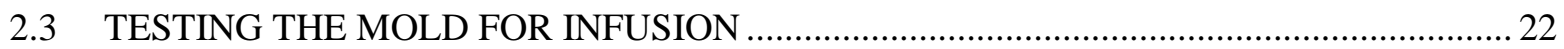

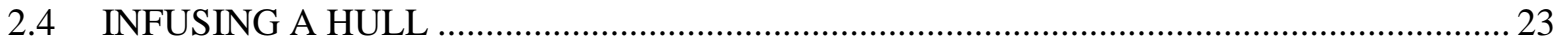

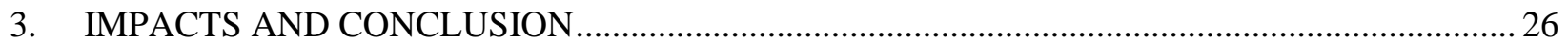

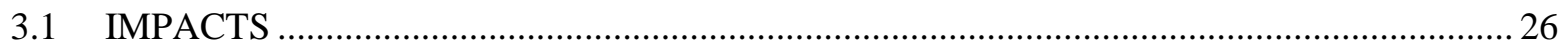

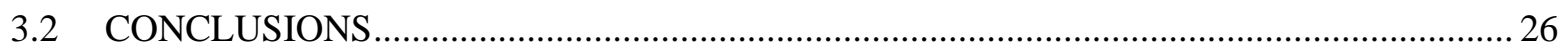

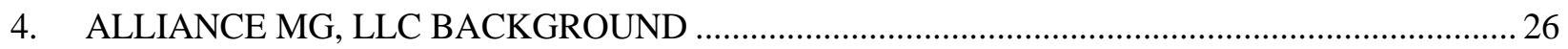




\section{LIST OF FIGURES}

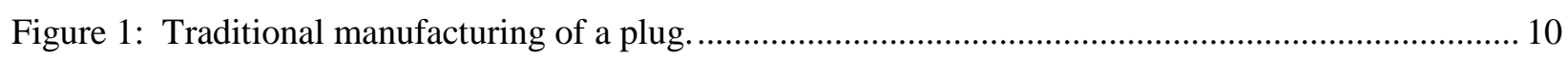

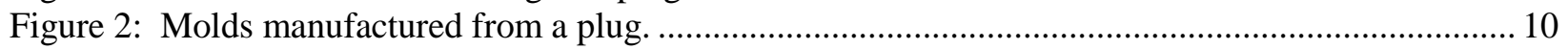

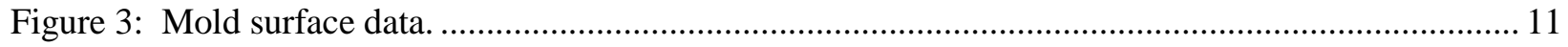

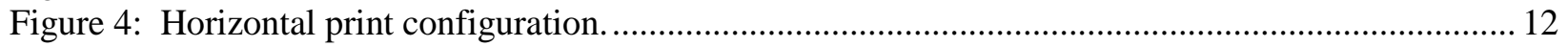

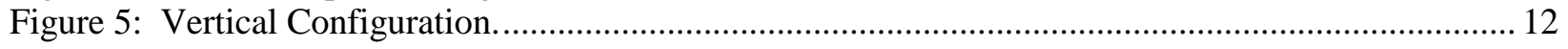

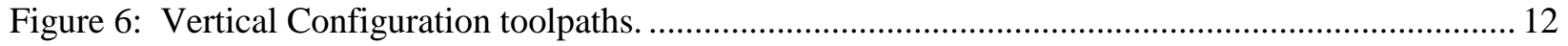

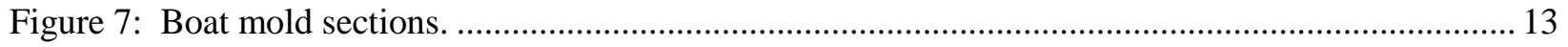

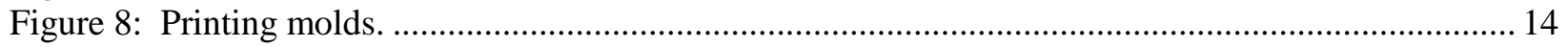

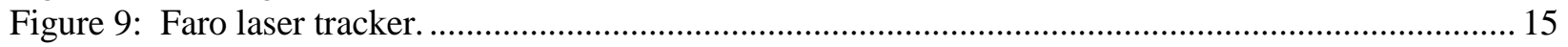

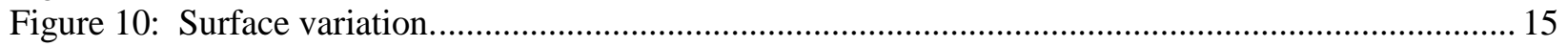

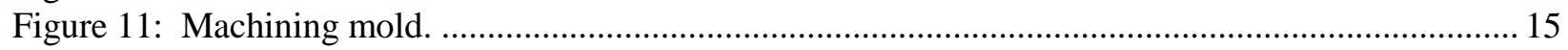

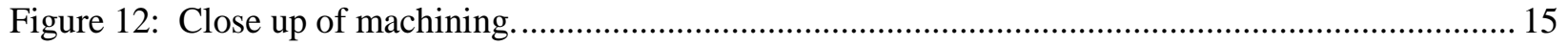

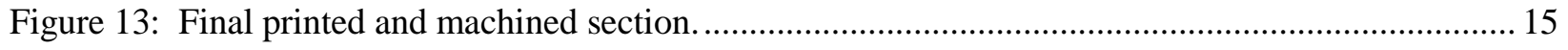

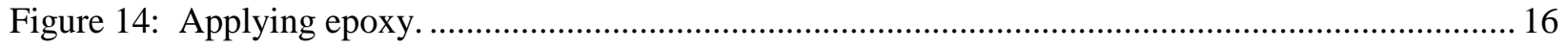

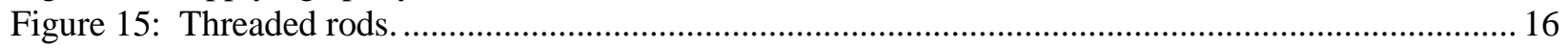

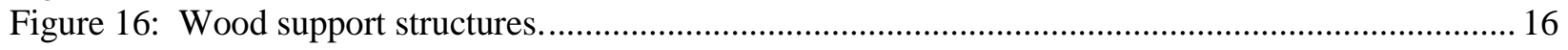

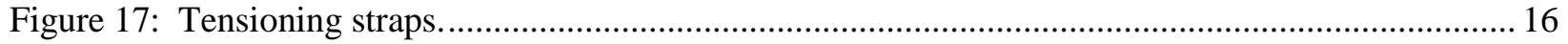

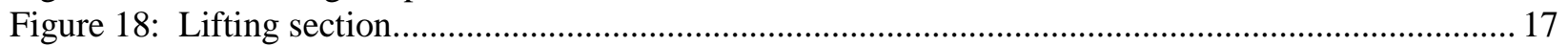

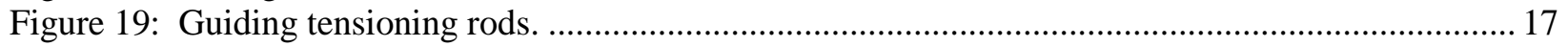

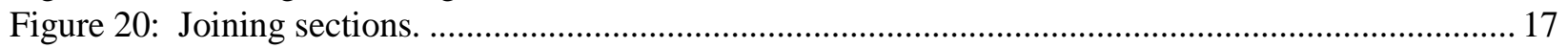

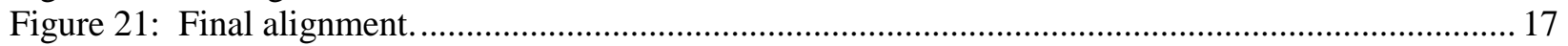

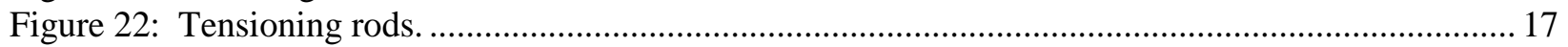

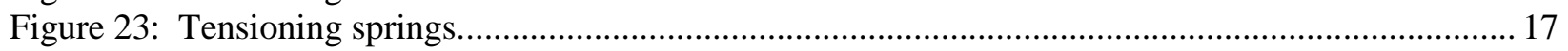

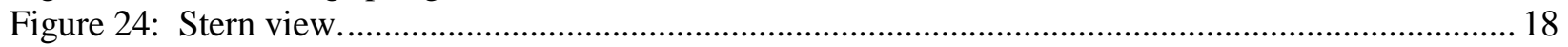

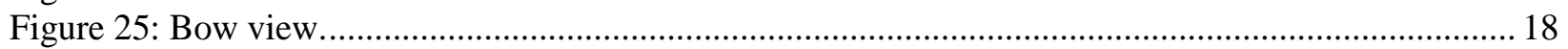

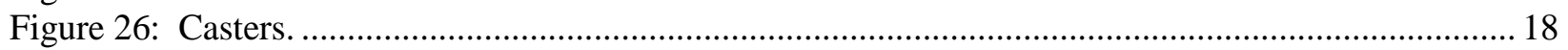

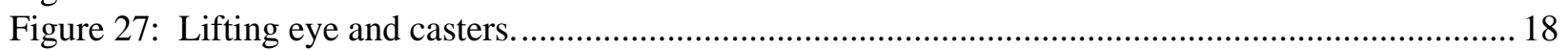

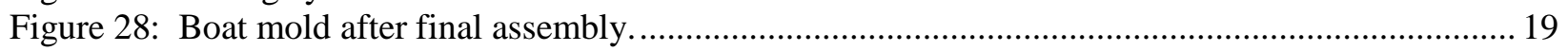

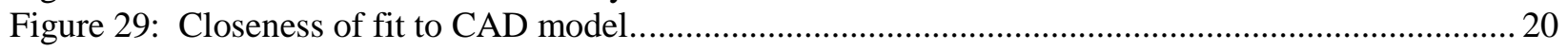

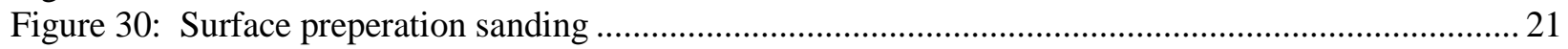

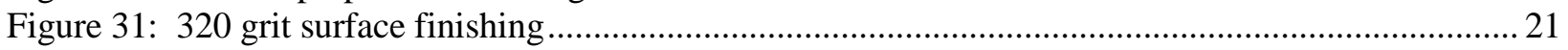

Figure 32: Mold coated with a vinylester mold surface agent ......................................................... 22

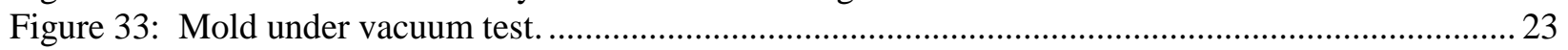

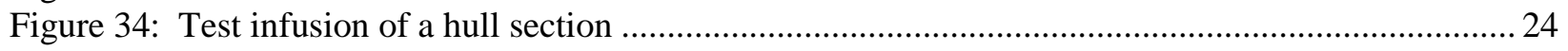

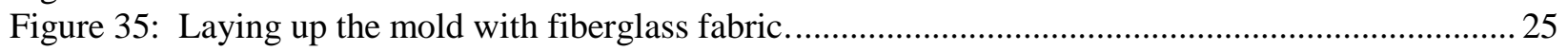

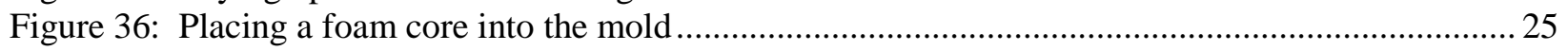

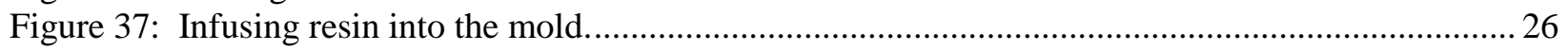

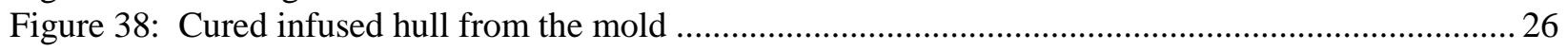




\section{ACKNOWLEDGEMENTS}

This Manufacturing Demonstration Facility User Facility Agreement NN-17-1062 was conducted as a Technical Collaboration project within the Oak Ridge National Laboratory (ORNL) Manufacturing Demonstration Facility (MDF) sponsored by the US Department of Energy Advanced Manufacturing Office (CPS Agreement Number 24761). Opportunities for MDF technical collaborations are listed in the announcement "Manufacturing Demonstration Facility Technology Collaborations for US Manufacturers in Advanced Manufacturing and Materials Technologies" posted at http://web.ornl.gov/sci/manufacturing/docs/FBO-ORNL-MDF-2013-2.pdf. The goal of technical collaborations is to engage industry partners to participate in short-term, collaborative projects within the Manufacturing Demonstration Facility (MDF) to assess applicability and of new energy efficient manufacturing technologies. Research sponsored by the U.S. Department of Energy, Office of Energy Efficiency and Renewable Energy, Advanced Manufacturing Office, under contract DE-AC0500OR22725 with UT-Battelle, LLC. 


\begin{abstract}
The goal of this phase 1 technical collaboration project was to explore the feasibility of using Big Area Additive Manufacturing (BAAM) to directly manufacture a boat mold without the need for coatings. All prior tooling projects with BAAM required the use of thick coatings to overcome the surface finish limitations of the BAAM process. While the BAAM process significantly lowers the cost of building the mold, the high cost element rapidly became the coatings (cost of the material, labor on coating, and finishing). As an example, the time and cost to manufacture the molds for the Wind Turbine project with TPI Composites Inc. and the molds for the submarine project with Carderock Naval Warfare Systems was a fraction of the time and cost of the coatings. For this project, a catamaran boat hull mold was designed, manufactured, and assembled with an additional 0.15 " thickness of material on all mold surfaces. After printing, the mold was immediately machined and assembled. Alliance MG, LLC (AMG), the industry partner of this project, experimented with mold release agents on the carbon-fiber reinforced acrylonitrile butadiene styrene (CF ABS) to verify that the material can be directly used as a mold (rather than needing a coating).
\end{abstract}

\title{
1. Boat Mold Manufacturing
}

This phase 1 technical collaboration project (MDF-TC-2017-126) was begun on July 25, 2017 and was completed on November 3, 2017 under ORNL user facility agreement NN-17-1062. The collaboration partner for this work Alliance MG, LLC (AMG) is a small business. The project successfully demonstrated Big Area Additive Manufacturing (BAAM) for directly printing boat molds without the need for coatings.

Traditional boat manufacturing is very similar to the process used for wind turbine blade manufacturing. The first step is to manufacture a plug, which is a model of the boat hull (see Figure 1). With conventional technology this process can take weeks to months. Once the plug is finished, it is coated with a fiberglass shell to make the final mold (see Figure 2). All prior tooling projects with BAAM required the use of thick coatings to overcome the surface finish limitations of the BAAM process. While the BAAM process significantly lowers the cost of building the mold, the high cost element rapidly became the coatings (cost of the material, labor on coating, and finishing). As an example, the time and cost to manufacture the molds for the Wind Turbine project with TPI Composites Inc. and the molds for the submarine project with Carderock Naval Warfare Systems was a fraction of the time and cost of the coatings. 


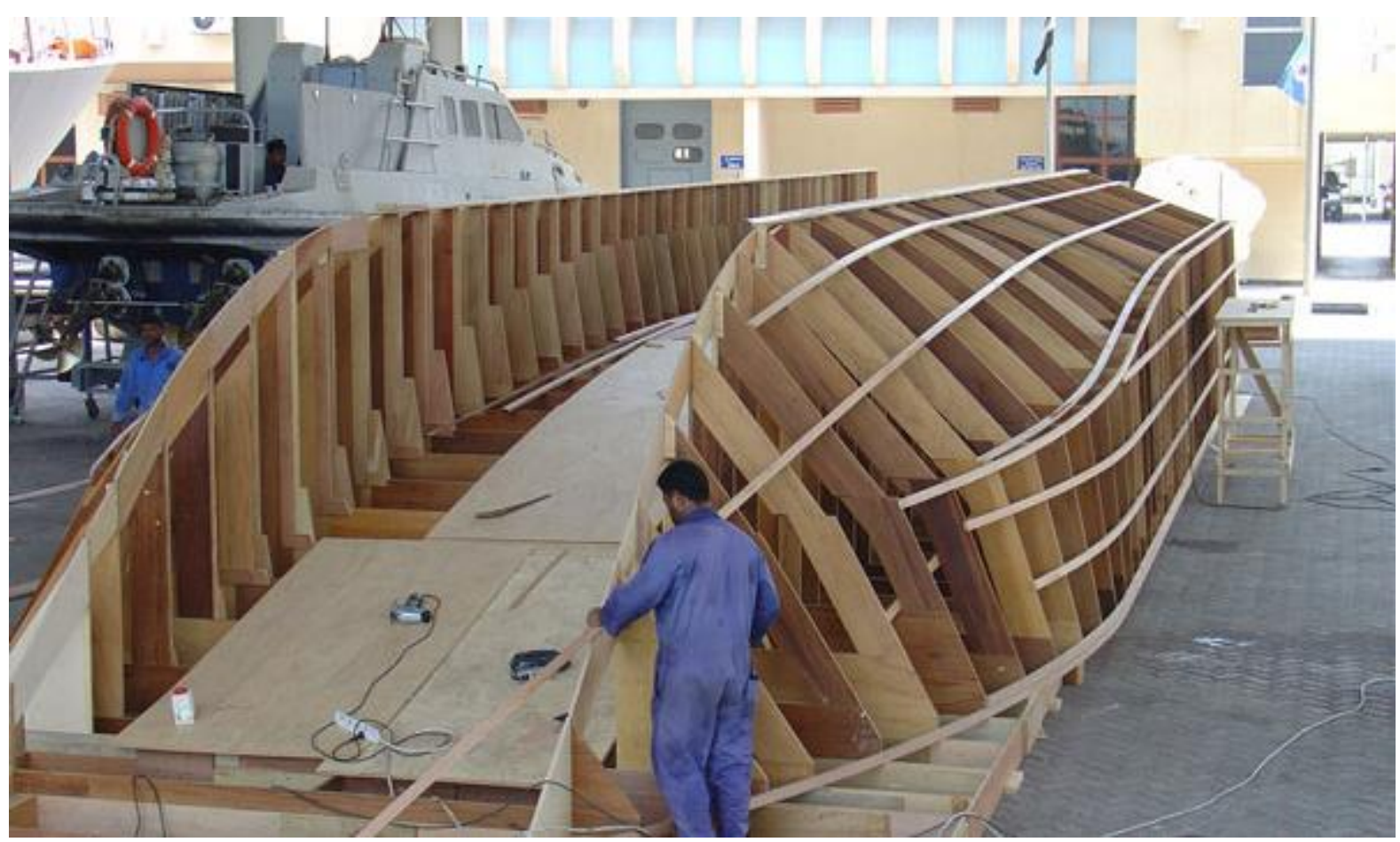

Figure 1: Traditional manufacturing of a plug.

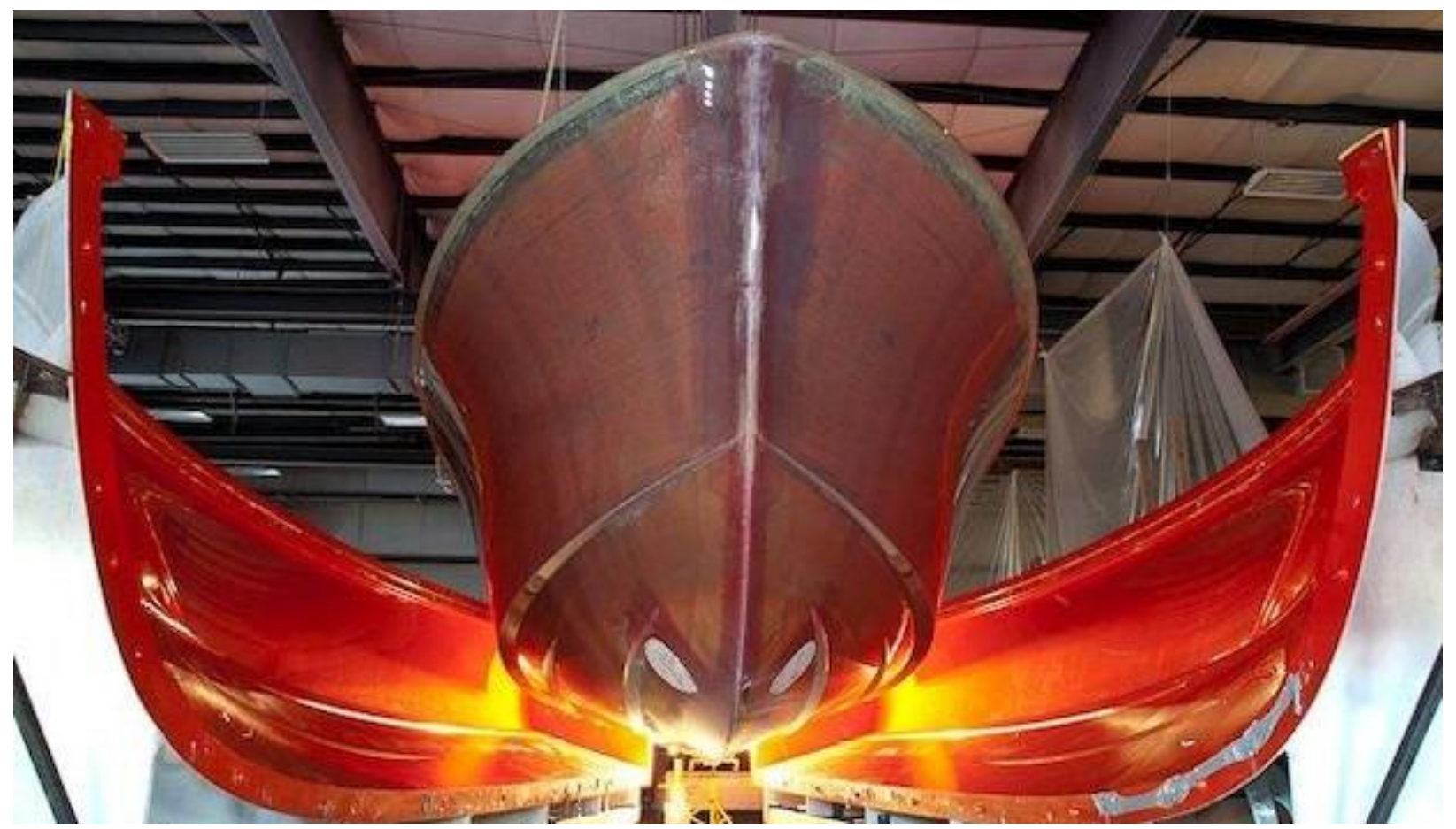

Figure 2: Molds manufactured from a plug.

The goal of this project was to directly manufacture a boat mold from the mold line data provided by AMG. Rather that coating the mold with fiberglass or an expensive filler material, the molds would be manufactured with approximately 0.15 " extra material and machined to the final target surface. The only 
post treatment would be the application of a mold release agent. The system also included an integrated tensioning system to address structural integrity rather than requiring an external frame.

\subsection{Boat Mold Design}

The boat mold tested is approximately 35 feet long. AMG provided ORNL the original mold surface data (see Figure 3).

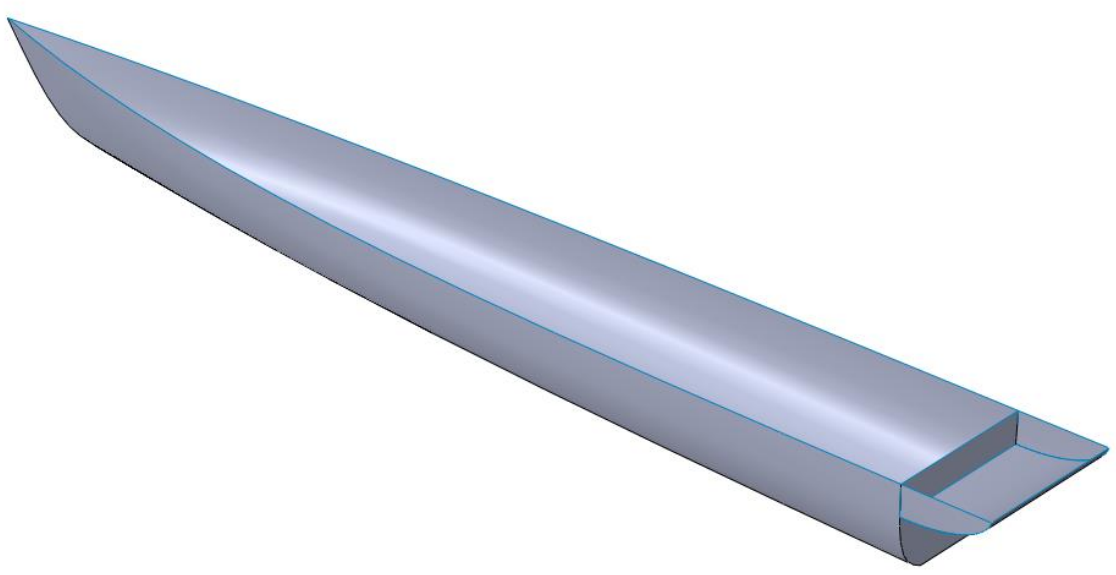

Figure 3: Mold surface data.

There are two fundamental limitations of the BAAM printer. First, the maximum build volume of the Cincinnati BAAM is 8 feet wide, 20 feet long, and 6 feet tall. Therefore, the mold had to be manufactured in sections. Second, the additive process results in a 'stair step' surface finish when the angles are very shallow (see Figure 4). The greatest accuracy between the model and the part is on the horizontal plane. Therefore, to achieve the best fit between the printed part and the model, the mold needed to be printed vertically (see Figure 5 and Figure 6 ).

Another limitation was the machining of the stern section. The stern comes to a fine edge, which resulted in very limited access for final machining to achieve the target surface finish. Therefore, the mold was designed into sections and printed vertically. To achieve the length, the mold was separated into six sections, each approximately 6 feet long, from bow to stern. Likewise, for the router to reach all surfaces, each of the six sections was made up of two parts: port and starboard. Therefore, the final mold is made up of a total of twelve printed parts (see Figure 7). 


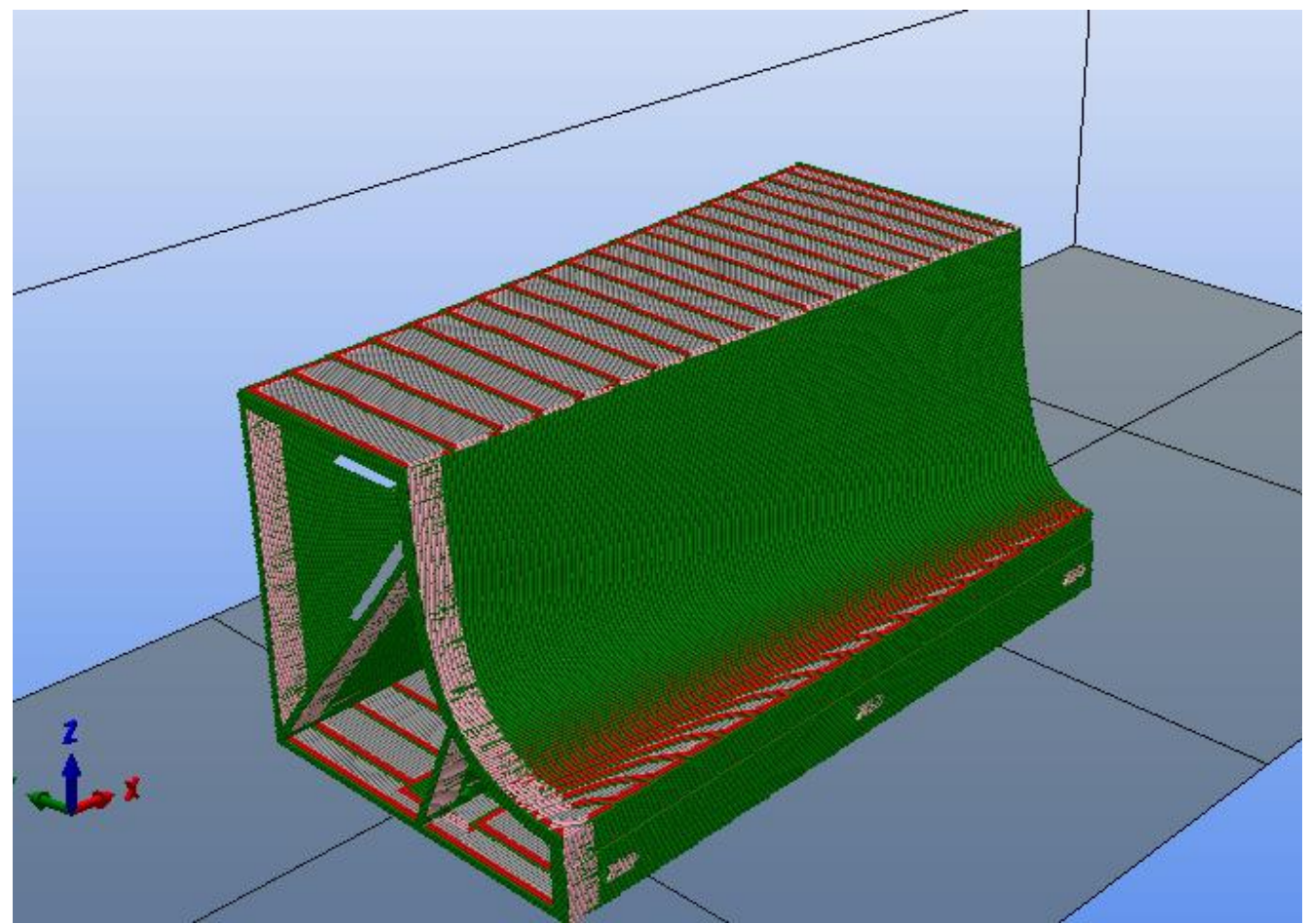

Figure 4: Horizontal print configuration.

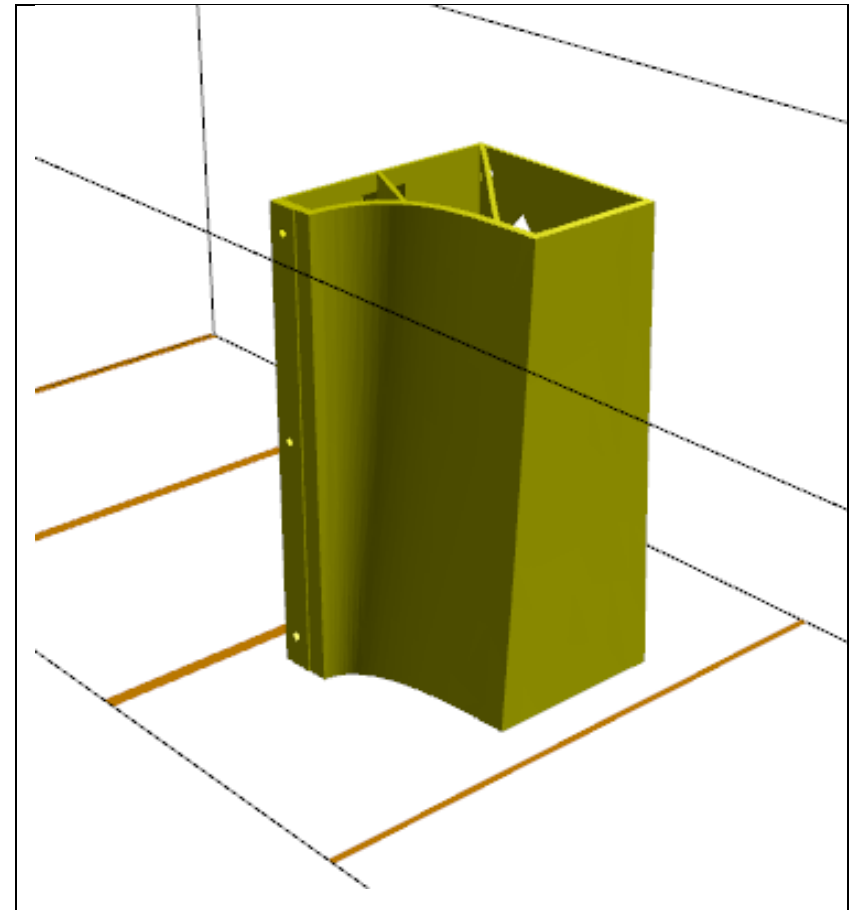

Figure 5: Vertical Configuration.

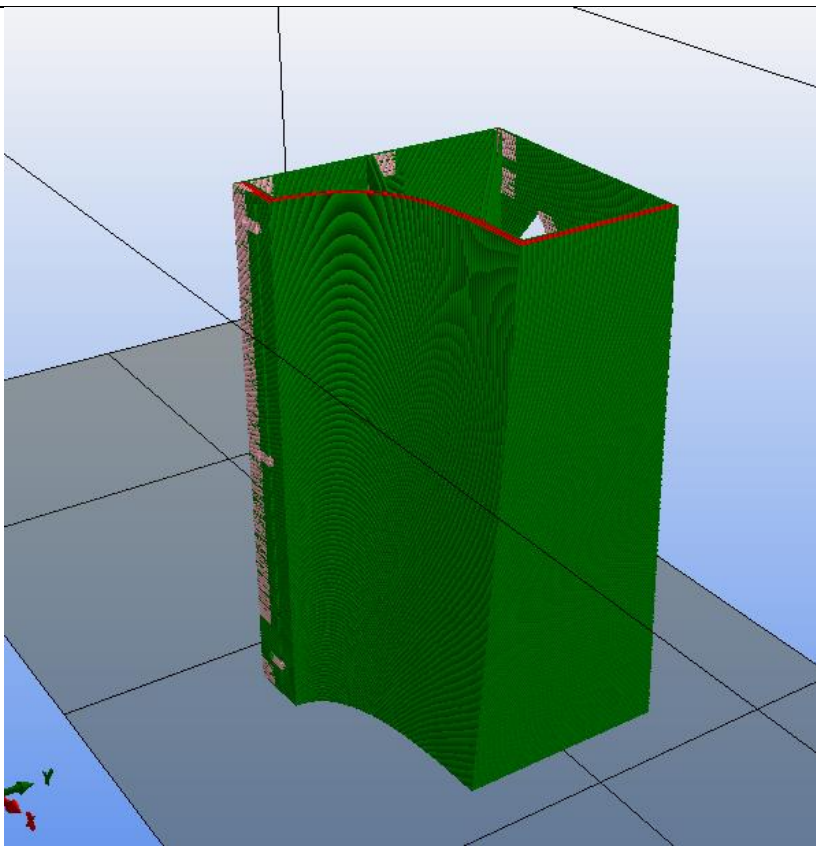

Figure 6: Vertical Configuration toolpaths. 


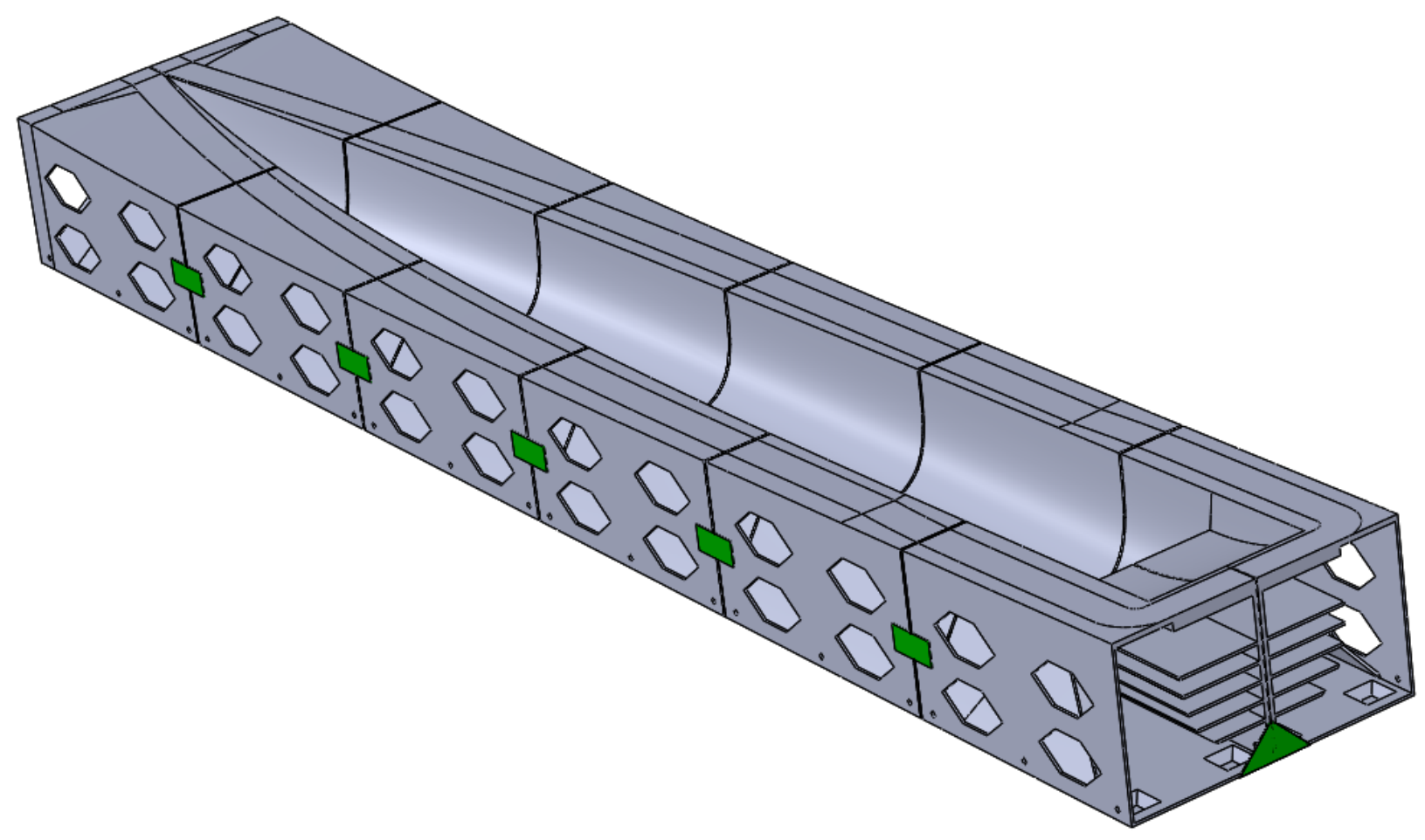

Figure 7: Boat mold sections.

\subsection{Boat Mold Printing}

The boat mold was printed on the Cincinnati BAAM system that has an $8 \mathrm{ft}$ x $20 \mathrm{ft} \times 6 \mathrm{ft}$ build volume. The material used for the process was $20 \%$ chopped carbon fiber reinforced ABS from Techmer ES (part number Electrafil J-1200/CF/20 3DP). The BAAM system used the 0.3" nozzle with a 0.15" layer height and 0.34 " bead width. The gantry moves with a $10.83 \mathrm{in} / \mathrm{sec}$ velocity for a $78 \mathrm{lb} / \mathrm{hr}$ flow rate. The molds were printed with 0.15 " extra material on the mold surfaces for machining. Since the bead widths are 0.34 ", the mid part of the bead is approximately 0.15 " from the edge of the print, which ensured the cut surface was near the center of the bead, minimizing defects and porosity. As shown in Figure 8 , three molds were printed simultaneously in approximately 12 hours. All of the mold sections were printed over a five day period. The total amount of material was $5500 \mathrm{lbs}$ costing approximately $\$ 5 / \mathrm{lb}$ (total material cost of $\$ 27,500)$. 


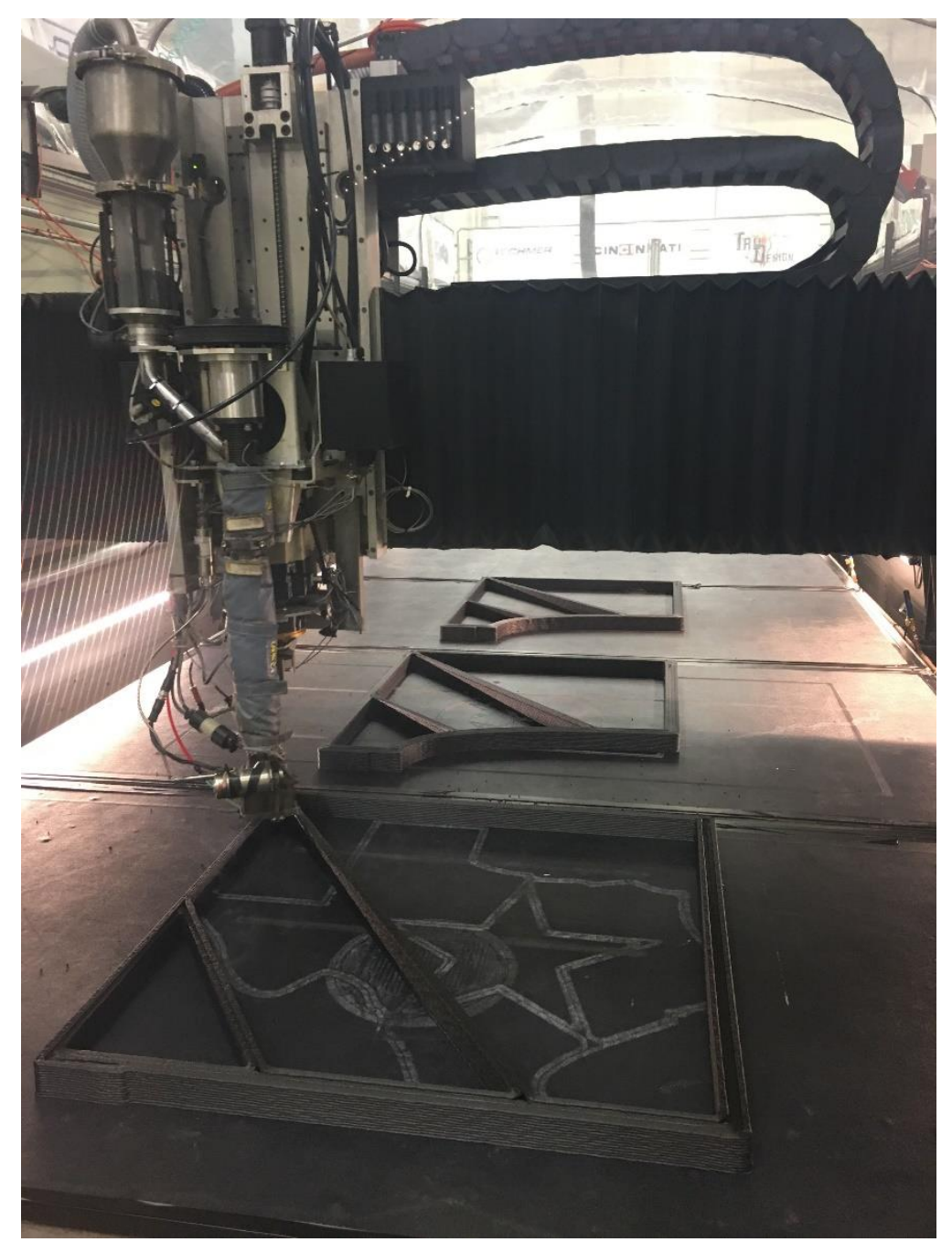

Figure 8: Printing molds.

\subsection{Boat Mold Machining}

Once the boat mold parts were printed, they were transported to a Thermwood router. A Fero laser tracker was used to locate and calibrate the printed part on the router table. The part is then placed on a table, and the tracking ball is moved over the surfaces of the mold. A point cloud is loaded into the Verisurf, which then finds the best fit between the model and the printed part. The laser tracker is likewise calibrated with respect to the router table. The actual printed model is then loaded into VisualMill. Surfaces are selected as well as the proper machining tool. A 0.5 " ball end mill with 0.050 " step over paths was used on the curved surfaces. Toolpaths are generated and loaded into the Thermwood router, which then machines the mold to the desired surface finish (see Figure 9 and Figure 10). Figure 11 and Figure 12 show the machining operation on one side of the printed section. 


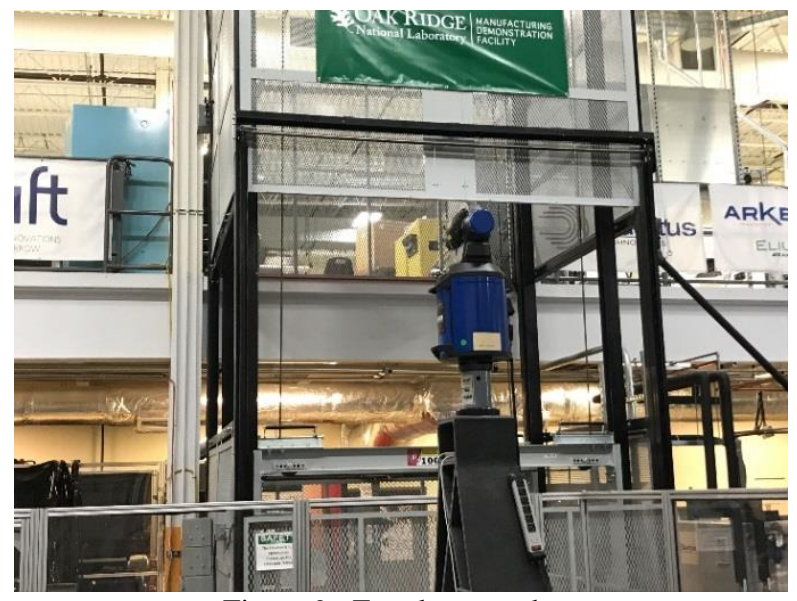

Figure 9: Faro laser tracker.

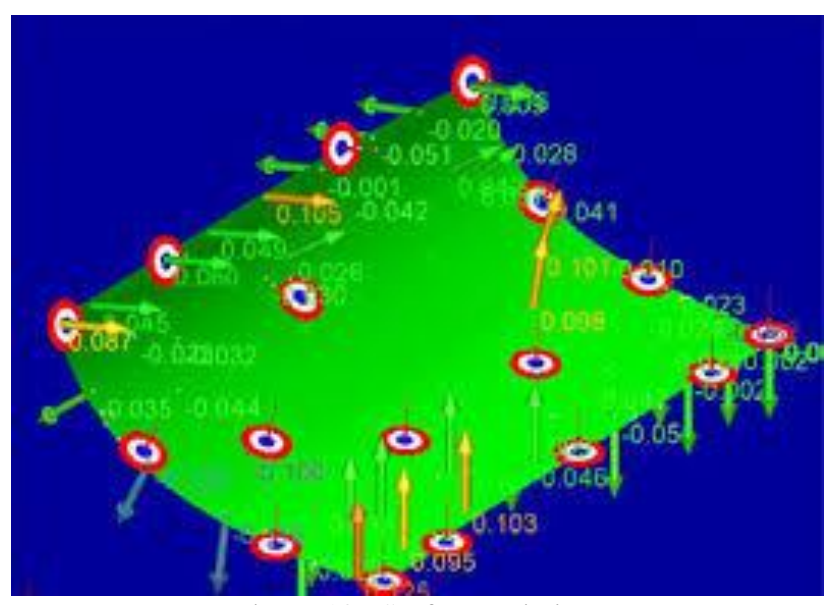

Figure 10: Surface variation.

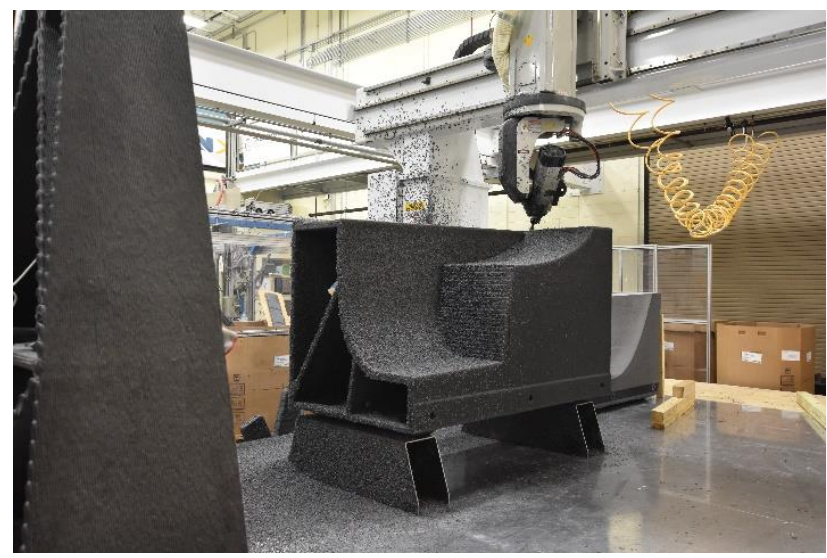

Figure 11: Machining mold.

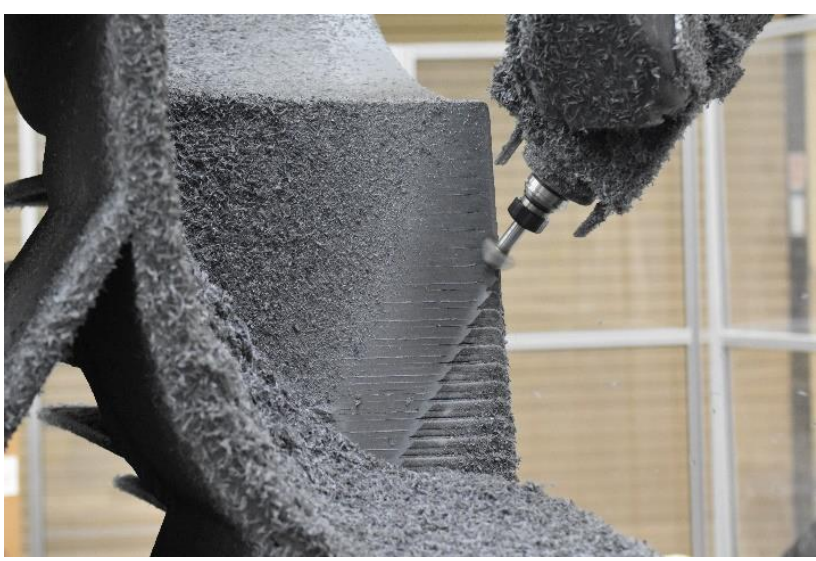

Figure 12: Close up of machining.

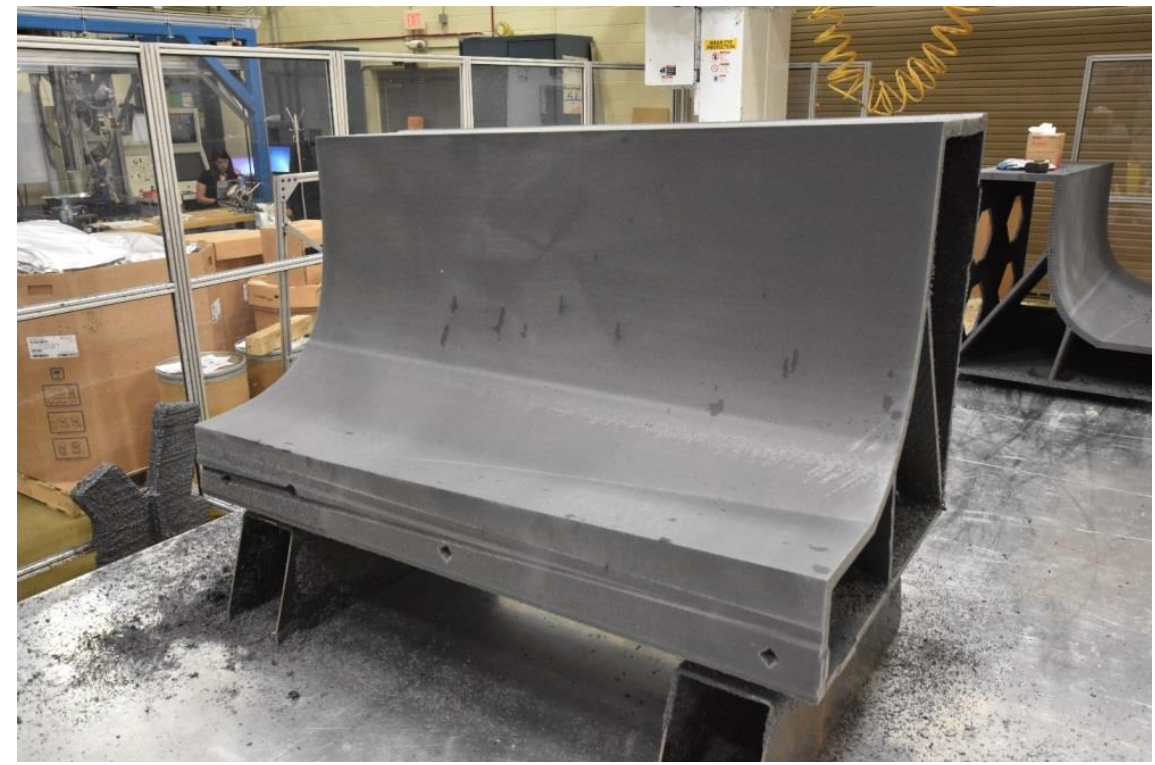

Figure 13: Final printed and machined section. 


\subsection{Boat Mold Assembly}

Threaded rods were used to hold the boat mold assembly together. Threaded rods were inserted horizontally to connect individual mold sections, and the resulting six, u-shaped sections were assembled using threaded rods that span the entire length of the mold. First, a set of three rods were inserted to hold the first starboard and port sections together. In addition, the team used PlioGrip Plastic Repair 10 epoxy from Volvoline on each of the seams. This adhesive is designed for ABS and provides 60 minute cure time to enable alignment adjustments during assembly. A team of two technicians lined each section up, applied the epoxy to the seams, joined the sections together, and tightened the threaded rods. To help with alignment, small inner tubes were placed on the ground between the mold and the floor to enable slight alignment adjustments (see Figure 14 and Figure 15). To help fully support the structure and maintain alignment, wood support beams were placed at the top of the mold to control the span across the top of the mold (see Figure 16). Finally, tensioning straps held the two sections together while the epoxy cured (Figure 17).

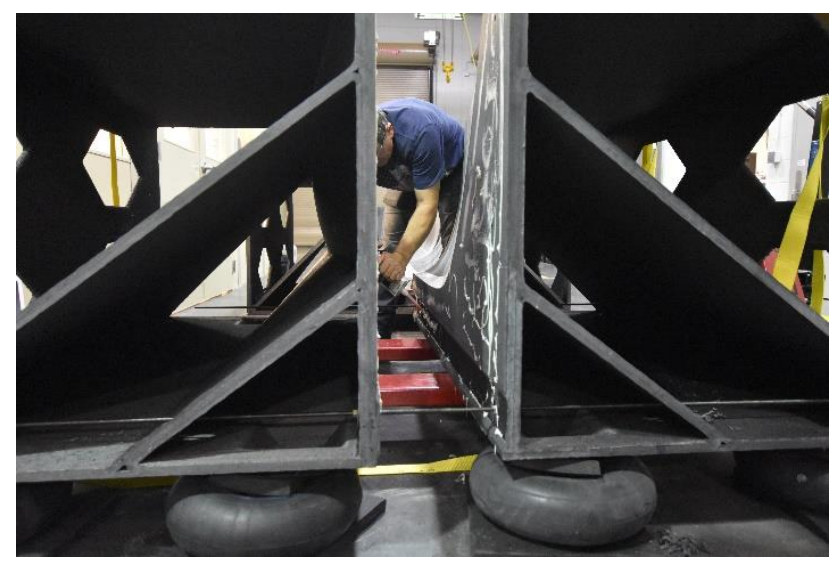

Figure 14: Applying epoxy.

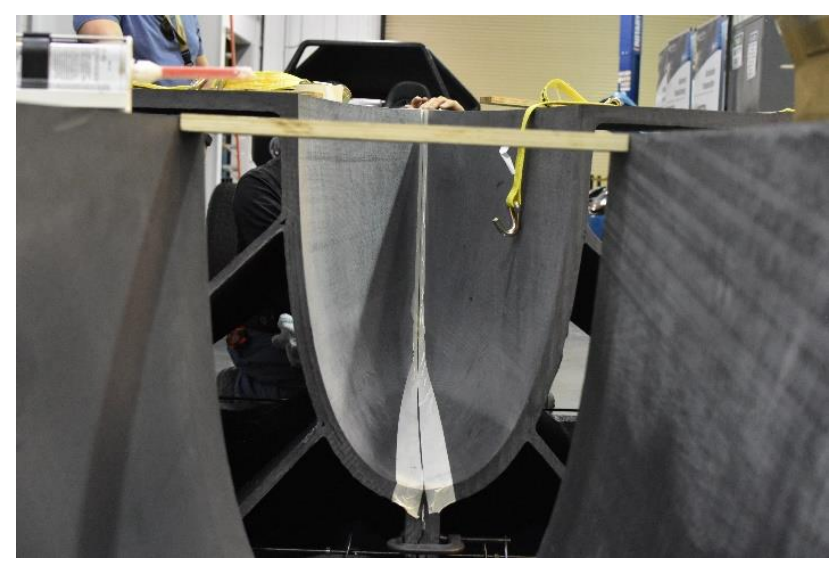

Figure 16: Wood support structures.

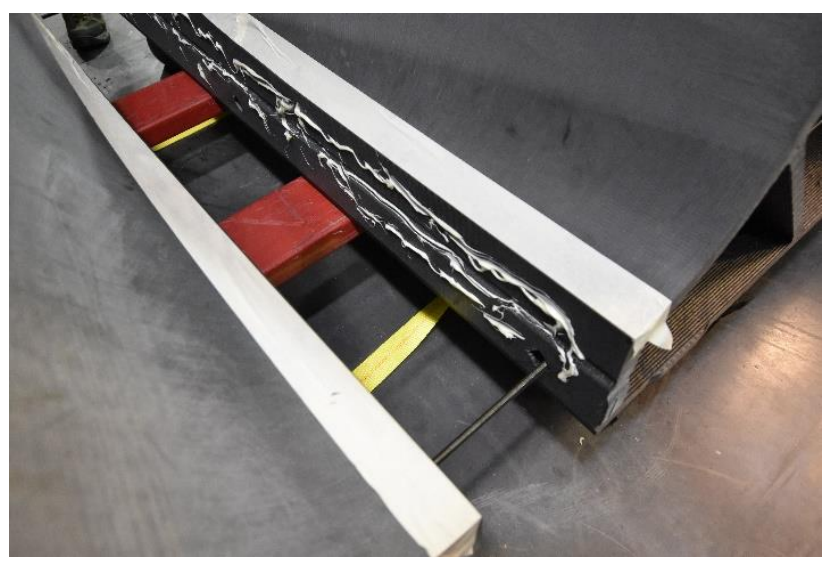

Figure 15: Threaded rods.

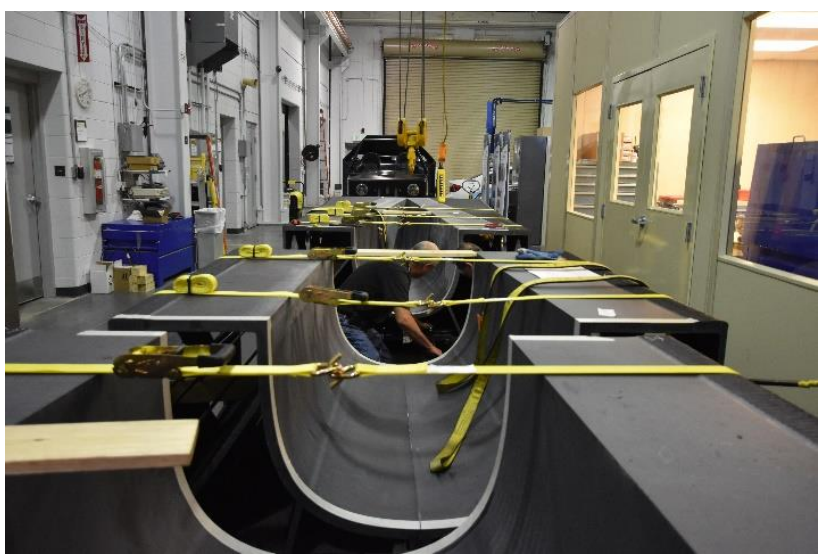

Figure 17: Tensioning straps.

Each section took approximately three hours to assemble, and sections were not handled for 24 hours to allow the epoxy to completely cure. The final step was the assembly of each section to make the full mold. The process started at the stern and worked backward, section by section, to the bow section (see Figure 18 through Figure 21). 


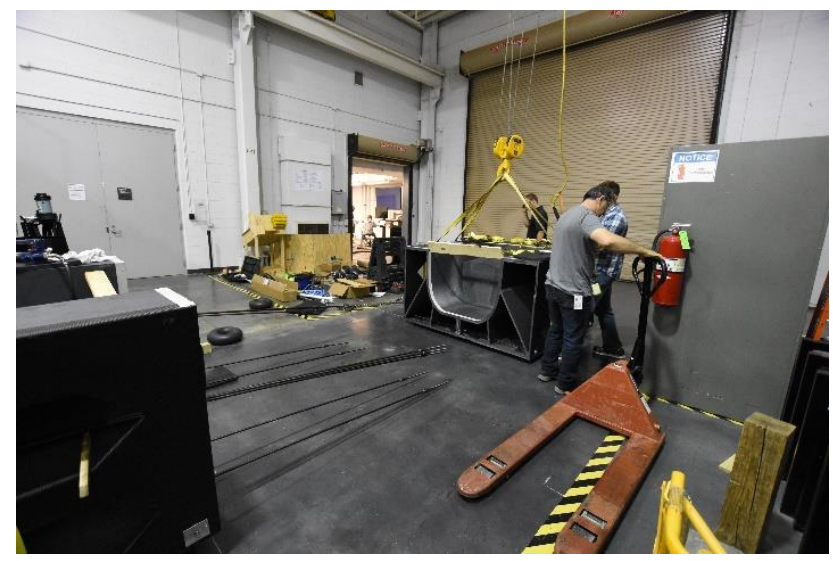

Figure 18: Lifting section.

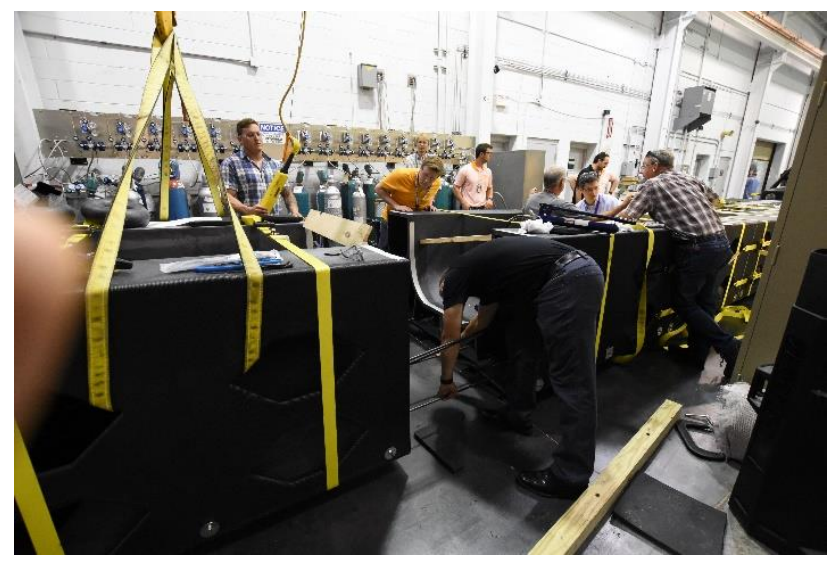

Figure 20: Joining sections.

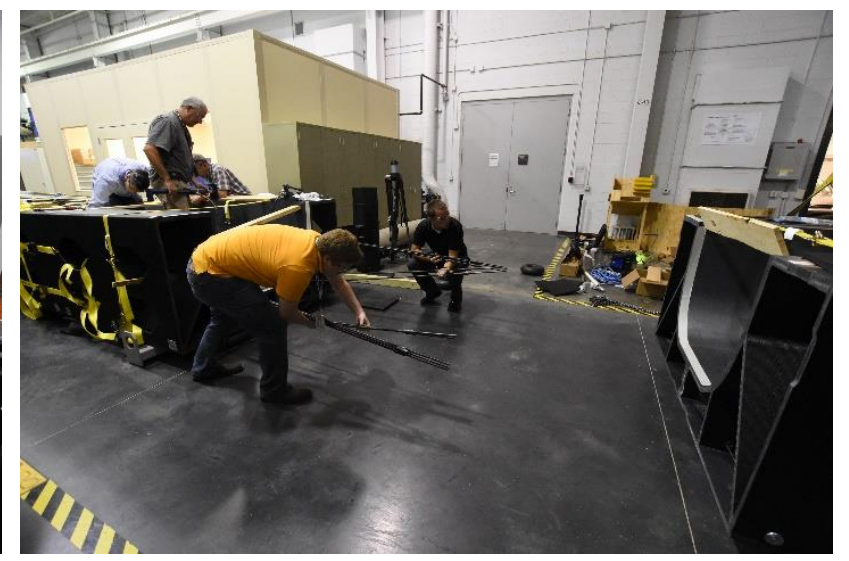

Figure 19: Guiding tensioning rods.

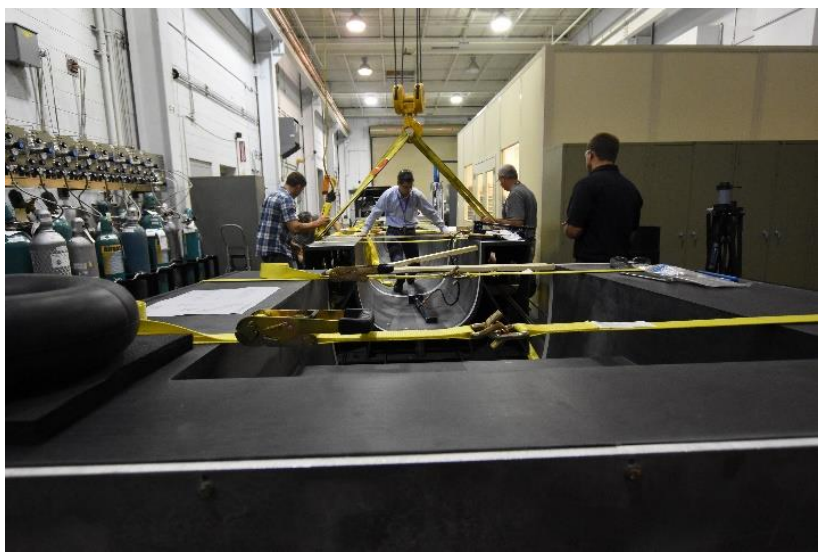

Figure 21: Final alignment.

To help distribute the loads of the long tensioning rods, aluminum bulkheads were manufactured and screwed onto the end sections (see Figure 22 and Figure 23). The threaded rods protruded through the bulkheads and were retained by a spring, washer, and nut. The springs enabled controlled tensioning on the rods to ensure loads were evenly distributed.

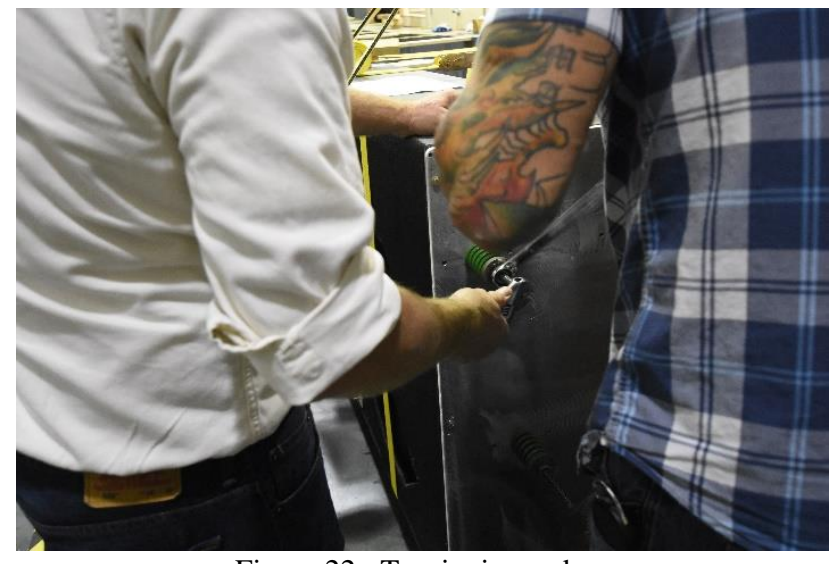

Figure 22: Tensioning rods.

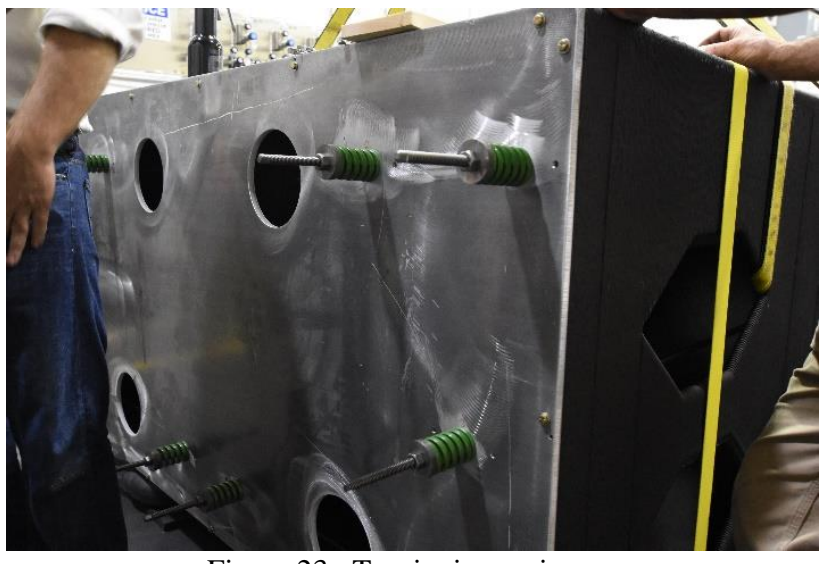

Figure 23: Tensioning springs.

Once the system was fully assembled, it was allowed to cure for approximately 24 hours before the straps were removed, and it was moved for transportation. 


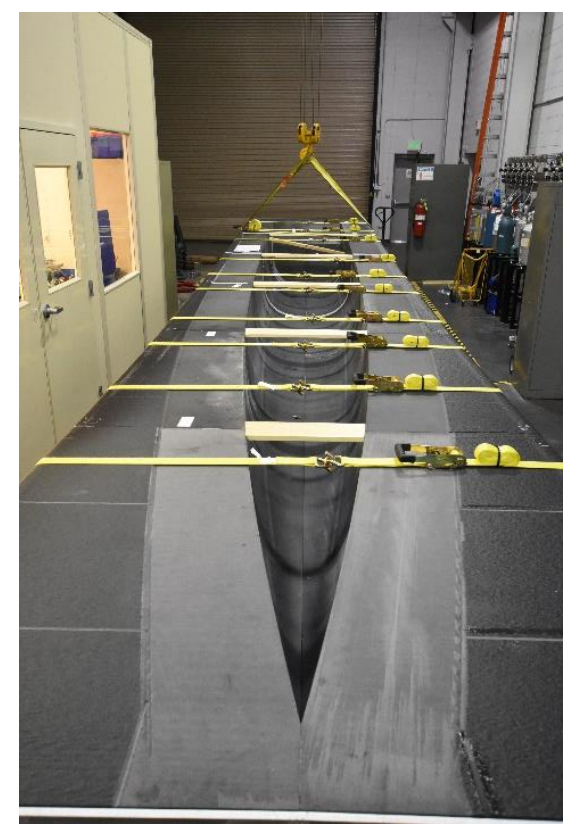

Figure 24: Stern view.

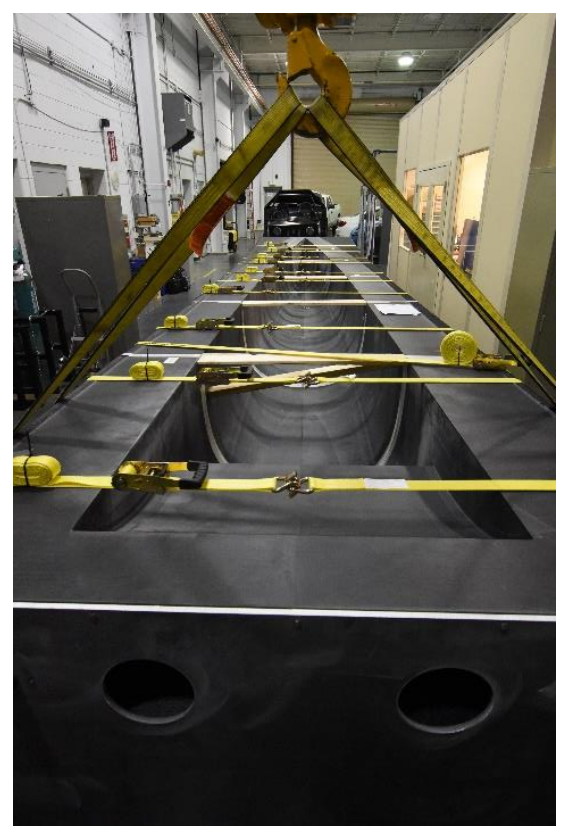

Figure 25: Bow view.

For transportation, a pair of steel beams with lifting eyes and attachable casters was attached below the mold. This enables ease of moving and lifting (see Figure 26 and Figure 27).

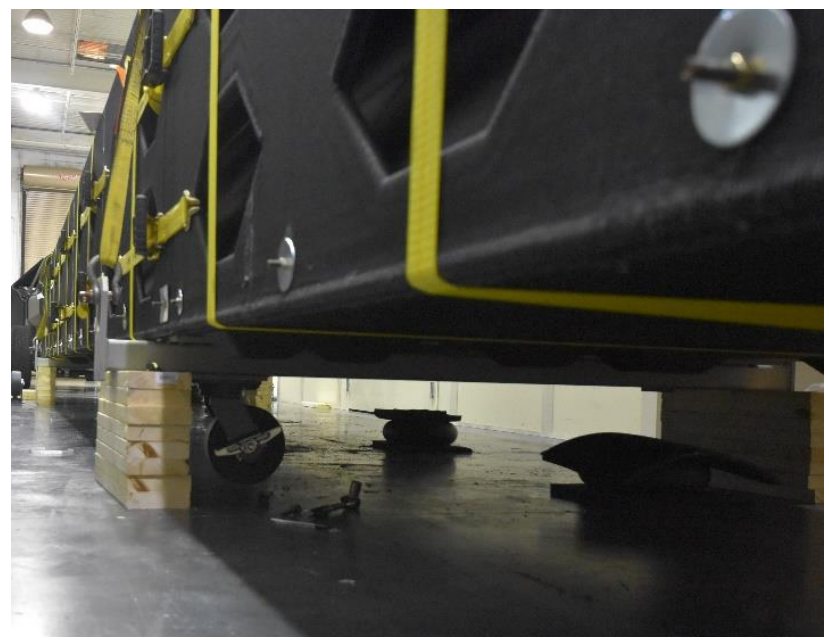

Figure 26: Casters.

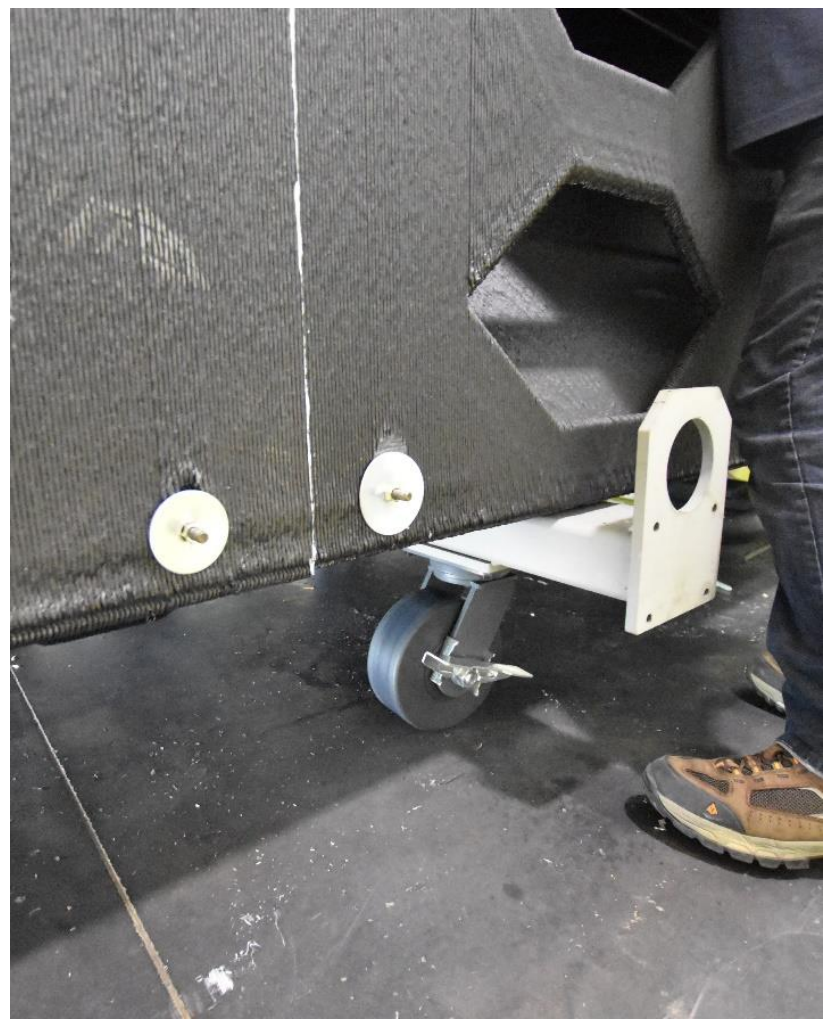

Figure 27: Lifting eye and casters.

The final mold is shown in Figure 28. 


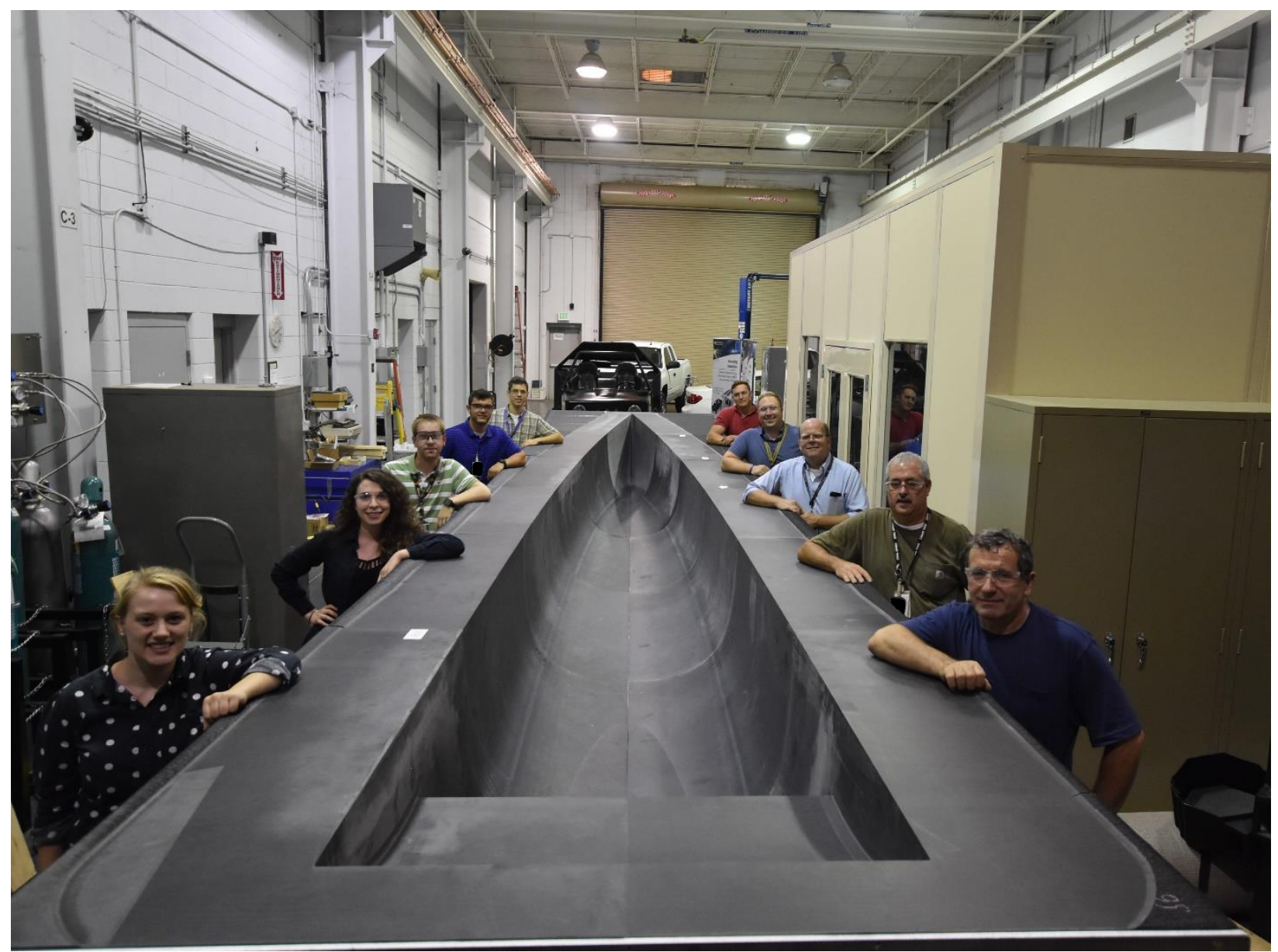

Figure 28: Boat mold after final assembly.

The final mold was scanned with a FARO laser tracking system and compared to the original CAD model. The fit had an average deviation of under 0.050" (see Figure 29).

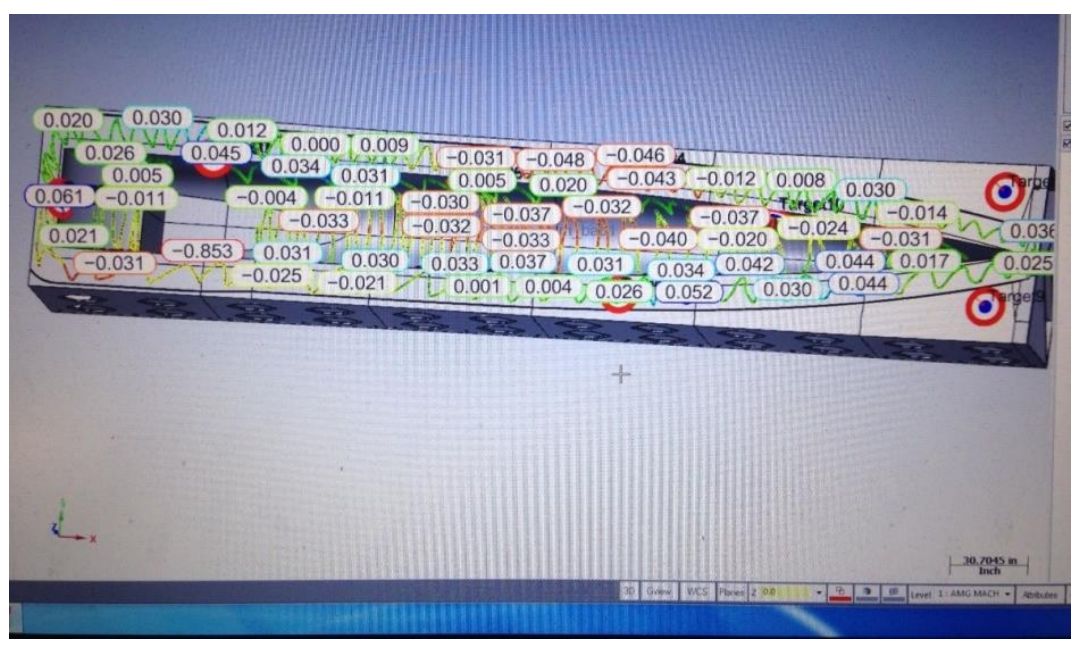

Figure 29: Closeness of fit to CAD model. 


\section{USING THE MOLD TO MANUFACTURE A BOAT HULL}

\subsection{OVERVIEW}

There are many different methods of production using molds. This project investigated a method known as resin infusion with the mold. Resin infusion uses the front or "A" surface of the mold directly as the molded surface.

This method requires the "A" surface of the mold to be prepared - sealed and polished - in order to provide a fair surface for the molded part. Sealing and polishing the "A" surface also ensures that the part can be removed safely from the mold without damage to either the mold or the molded part. After surface preparation, the mold can be used to produce parts by placing layers of fiberglass or other composite fabrics into the mold, along with structural core materials.

Once all the materials that will comprise a part have been placed into the mold, an airtight bag is placed on top of the layers, and sealing tape is used to seal the bag directly to the mold before the air within the bagged space is evacuated using a vacuum pump. Once a stable vacuum has been achieved, resin is allowed to flow into the bag under vacuum, and the resin is pulled throughout the schedule of materials previously laid-up into the mold. Since the whole infusion process occurs under vacuum, the resulting part is lean and uniformly integrated under atmospheric pressure.

\subsection{SURFACE PREPARATION}

After assembly at the ORNL MDF, the boat mold was transported on a flatbed, air-suspension truck to a finishing facility. Using air pressure tools and abrasives, the surface of the mold was polished initially to a finish of 180 grit (Figure 30), and ultimately to a 320 grit surface finish (Figure 31).

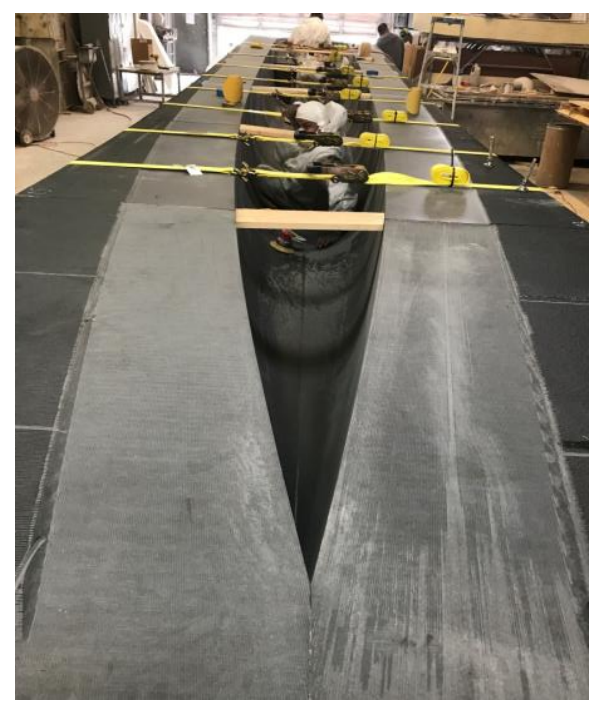

Figure 30: Surface preparation sanding. 


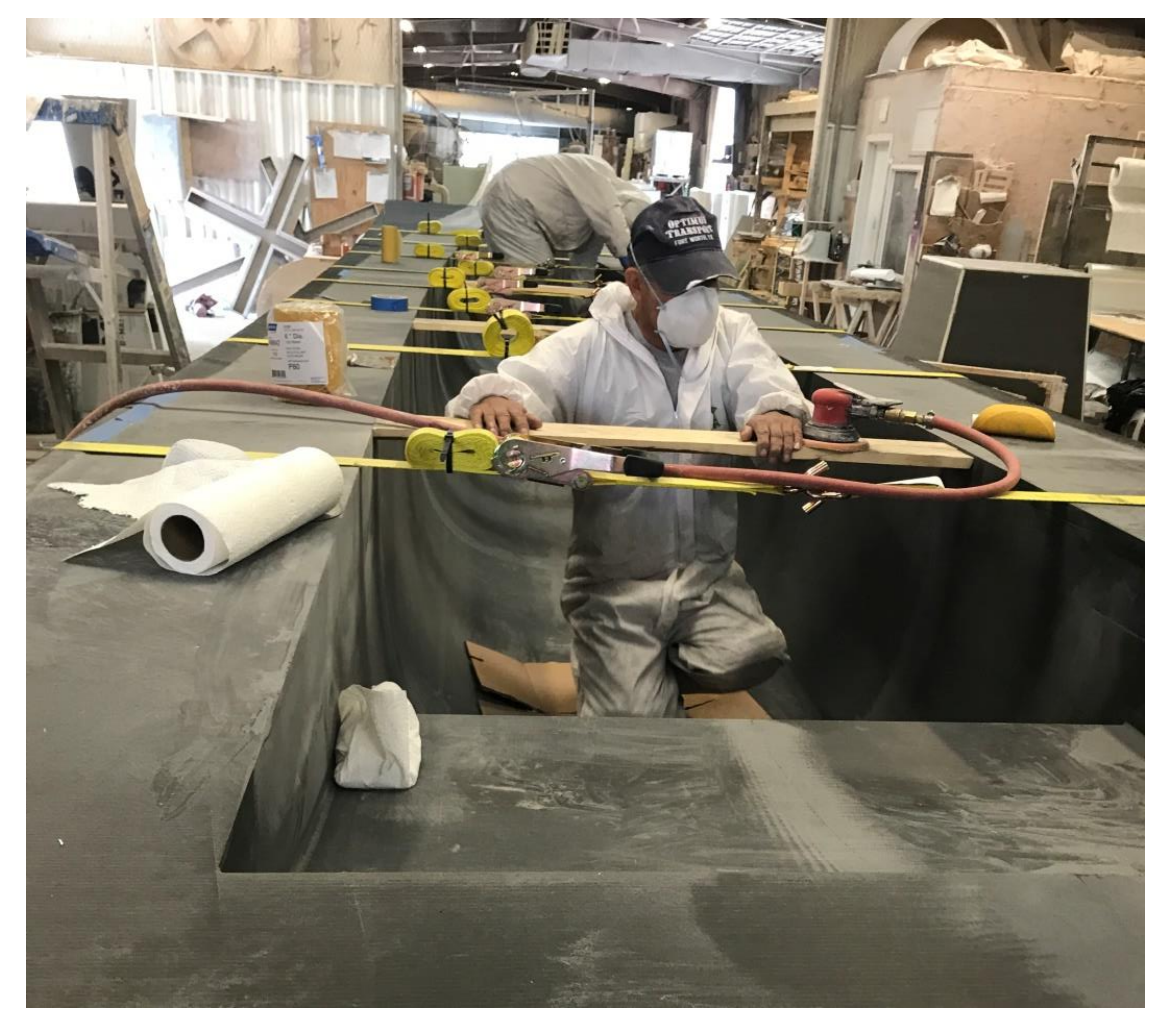

Figure 31: 320 grit surface finishing.

After sanding, the mold was coated with a commercially available vinylester mold surface agent from Hawkeye Industries (Figure 32).

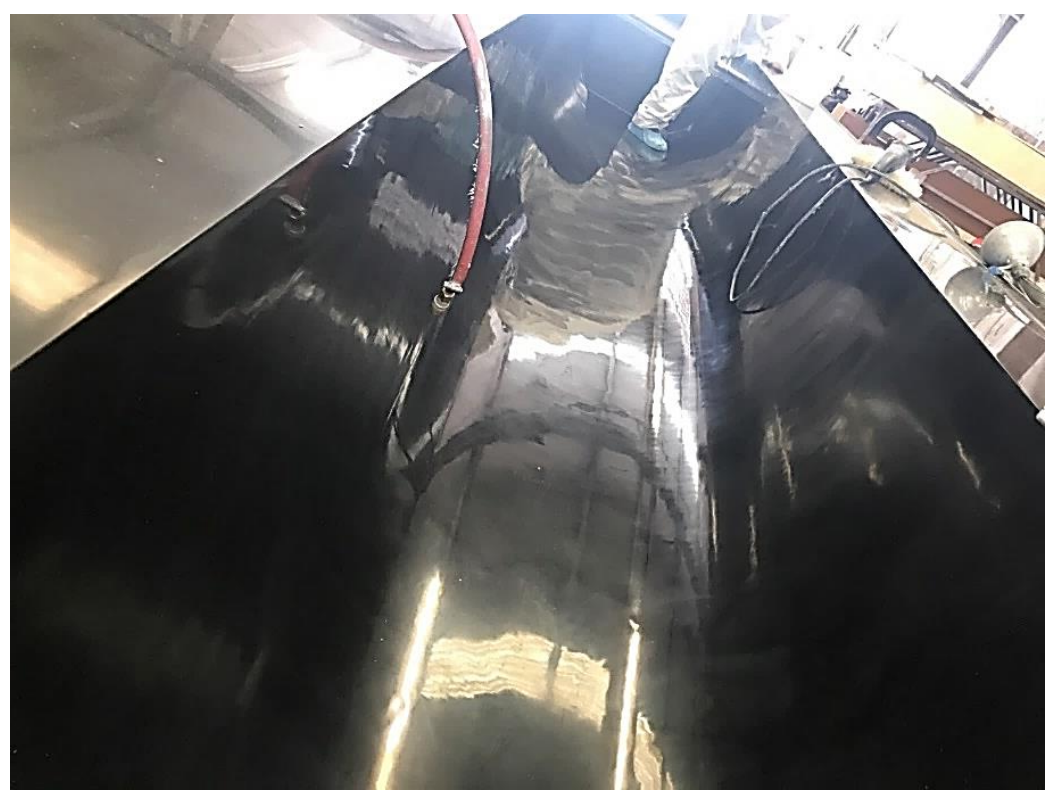

Figure 32: Mold coated with a vinylester mold surface agent. 


\subsection{TESTING THE MOLD FOR INFUSION}

To confirm the mold was ready to make parts, it was covered with a vacuum bag and placed under vacuum (Figure 33). The mold must hold a vacuum without loss of vacuum for a specified period of time before it is ready to manufacture a part.

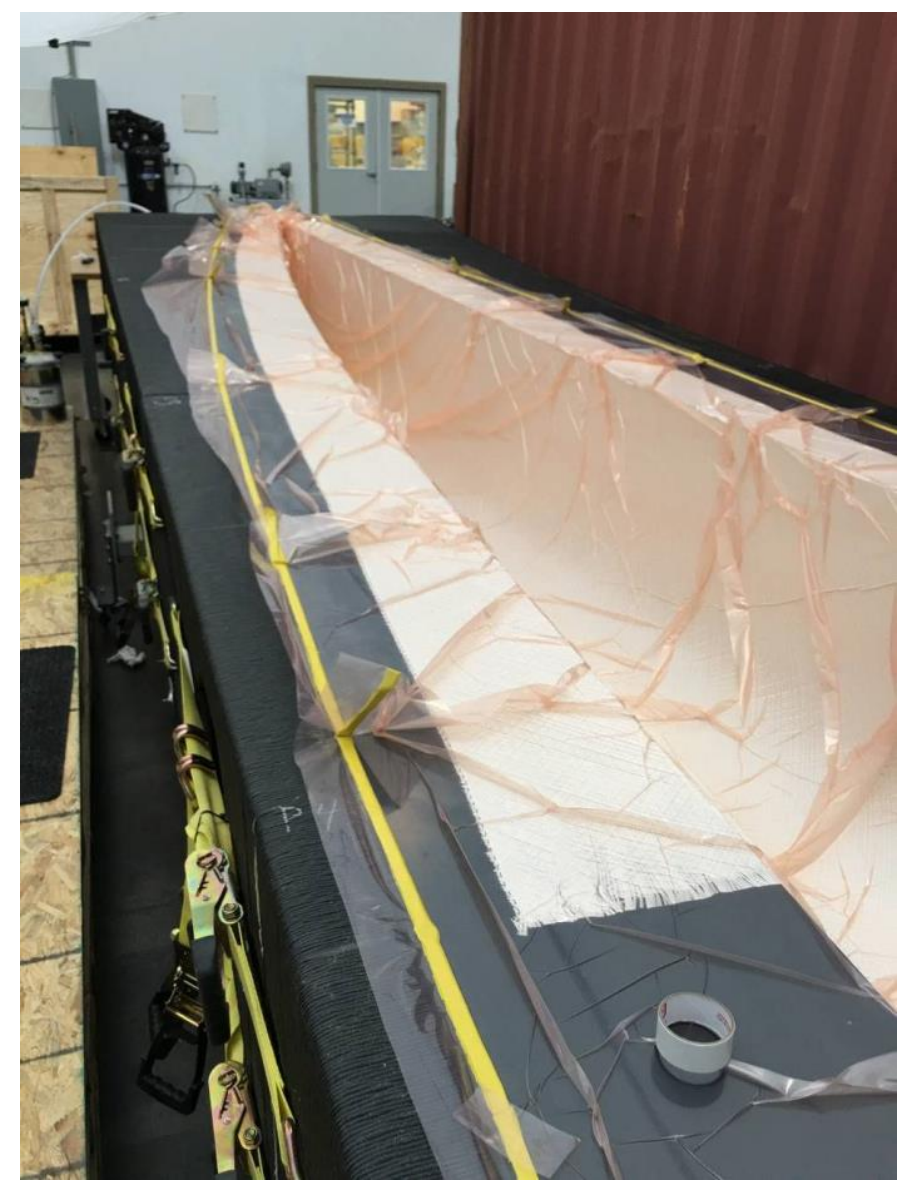

Figure 33: Mold under vacuum test.

Once the vacuum test was completed, a test piece was infused, to simulate a complete infusion. Using composite fabrics, foam cores, and a resin system, a section of the full boat hull was infused.

To ensure a clean release from the mold, the prepared mold surface was first coated with a release agent before fabrics and a core were applied. Finally, a vacuum bag was placed over the entire section, and resin was introduced once a vacuum had been established (Figure 34). 


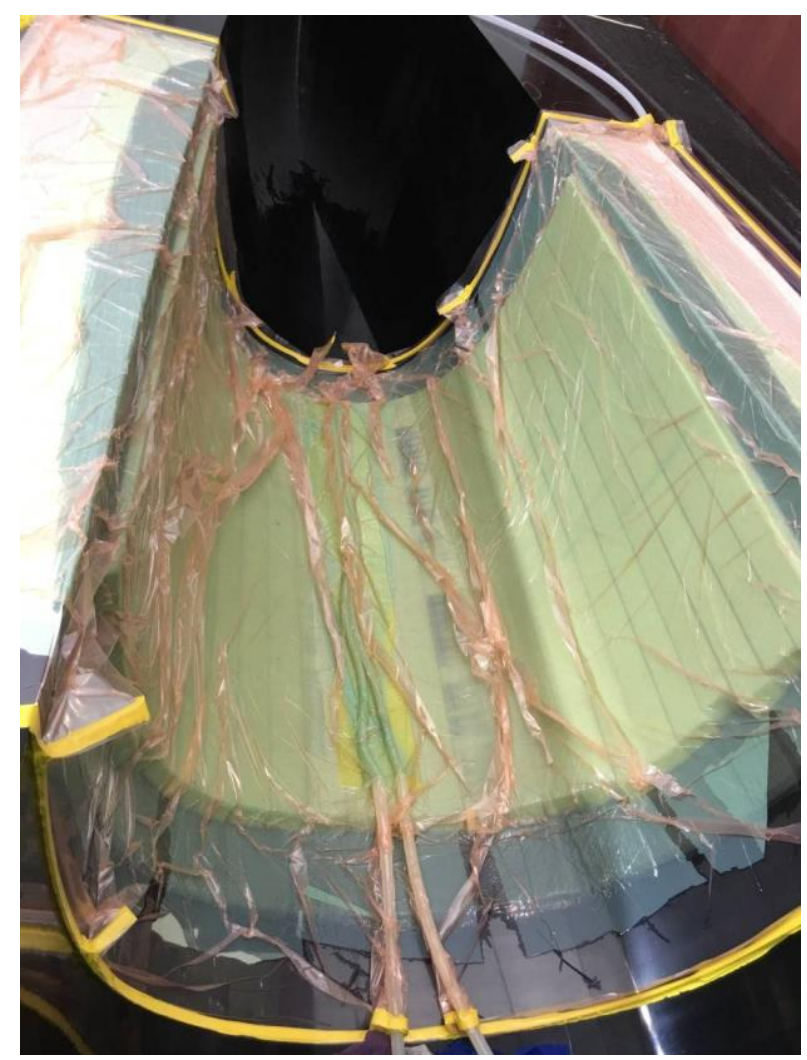

Figure 34: Test infusion of a hull section.

After infusion, a resting period was necessary to allow the part to cure in the mold.

\subsection{INFUSING A HULL}

The test infusion provided the first instance to test all elements of the mold. Applying the results from the test infusion, fabrics and core were laid into the mold completely, as shown in Figures 35-38. 


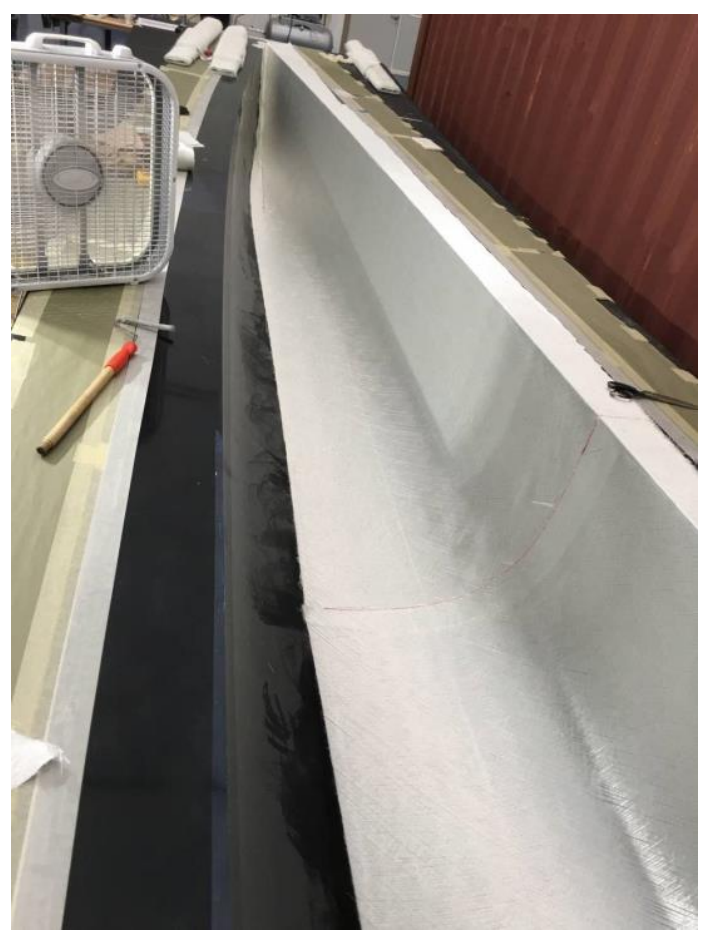

Figure 35: Laying up the mold with fiberglass fabric.

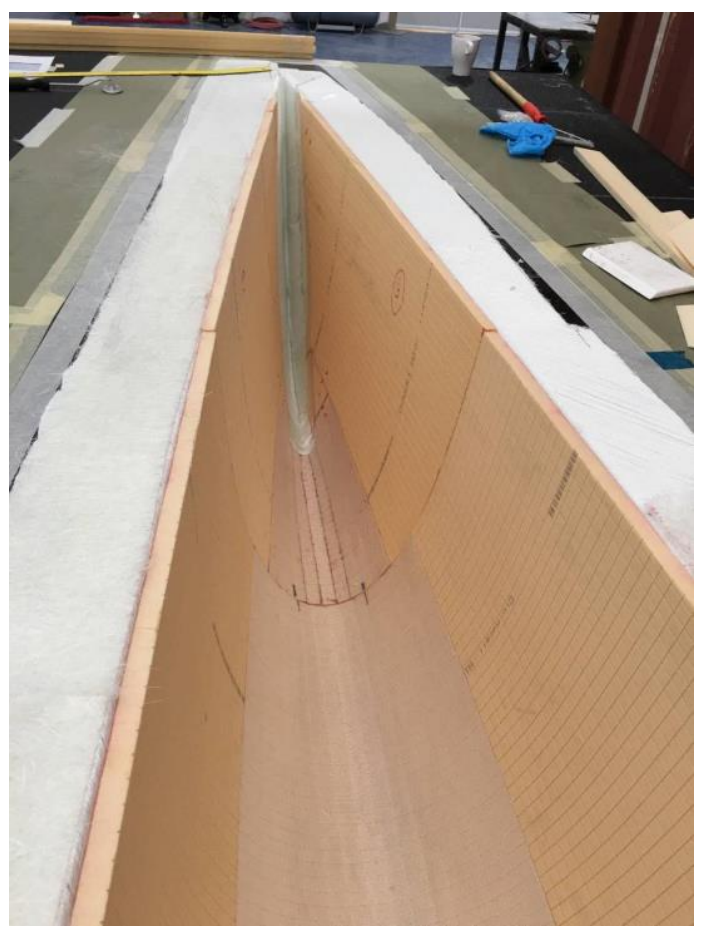

Figure 36: Placing a foam core into the mold. 


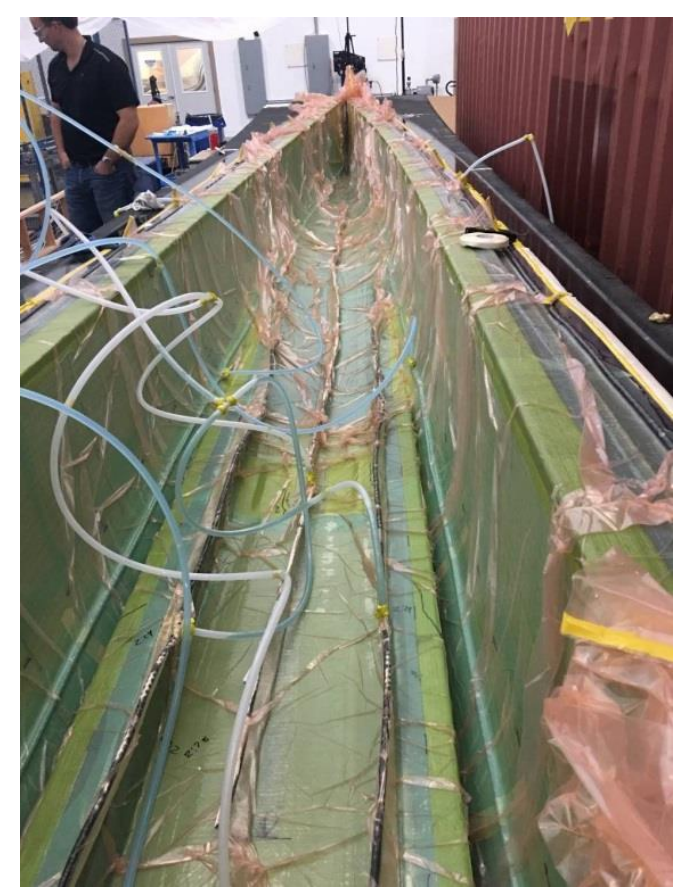

Figure 37: Infusing resin into the mold.

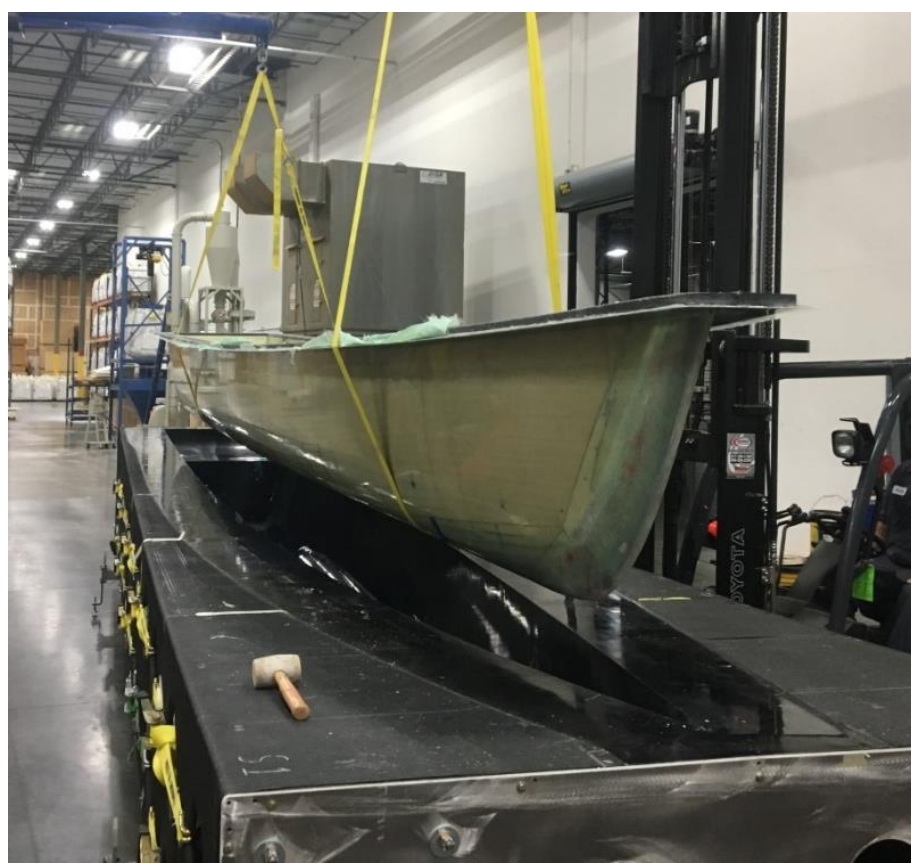

Figure 38: Cured infused hull from the mold.

After infusion, the mold was inspected for damage. It was found to have developed "pneumatic cracks" and showed evidence of air leaks in two areas. Notably, these "pneumatic cracks" were not obviously visible. These "pneumatic cracks" were caused by the incorrect application of the coating onto the mold, so they transferred to the hull. However, these are hairline cracks and do not impact the integrity of the mold. This issue can be solved by either reapplying the coating to the hull after every part is pulled or by applying a stronger coating or slightly thicker coating. 


\section{IMPACTS AND CONCLUSION}

\subsection{IMPACTS}

The goal of this project was to explore directly using the printed material for mold manufacturing without the need for expensive coatings. A mold was created that could be used without the use of thick coatings to overcome the surface finish limitations of the BAAM process. Elimination of that coating step would significantly reduce the manufacturing cost and lead time associated with BAAM tooling. In addition, the project demonstrated the ability to print a large mold in sections without the need for a subframe.

\subsection{CONCLUSIONS}

The project demonstrated that it is possible to use an additively manufactured, free-standing mold without thick coatings to produce mold parts, provided that attention is paid to the following critical steps:

- The design of the mold itself must lend itself well to supporting the structure of the printed mold

- The mold must have a minimum number of sections if the 3D printer cannot print the entire mold at once

- Bracing and tensioning of the mold is critical. The mold in service will come under significant mechanical stress in transport and in use

- The layer-by-layer nature of 3D printing of the mold provides only a mechanical bond between the printed layers. These layers may not be airtight, and if infusion is to be used for making mold parts, proper sealing of the mold surface is of the utmost importance

- If the mold will be exposed to heat or chemical exotherm, care must be taken to ensure processing temperatures do not exceed the thermal capabilities of the 3D printing material

- If molds with complex curves are to be printed, care must be taken to ensure that demolding does not become problematic as result of the mold's shape

- The mold will require maintenance in use. The extent of this maintenance is not established and is the subject of further analysis by AMG

\section{ALLIANCE MG, LLC BACKGROUND}

Alliance MG (AMG) provides complex project management and technology incubation services. The company is working to evolve the process of boat building in order to reduce the cost and complexity of building boats, while at the same time improving product quality, shortening time-to-market, and reducing the price of boats for consumers. Alliance MG LLC's managing director is Stephen Wu. Alliance MG, LLC is another venture of Stephen Wu's that will develop additional manufacturing technology in the boating industry. 